\title{
A pharmacognostic approach for mitigating pancreatic cancer: emphasis on herbal extracts and phytoconstituents
}

\author{
Shruti Gupta, Atul Kumar and Kiran Kumar Tejavath *
}

\begin{abstract}
Background: Pancreatic cancer is studied as one of the most lethal cancers with currently no control of its lethality, mainly due to its late diagnosis and lack of foolproof treatment processes. Despite continuous efforts being made in looking for therapies to deal with cancer, it keeps on being a labyrinth for the researchers. Efforts like discovering new treatment options, repurposing existing drugs, are continuously made to deal with this cancer.

Main body: With the urge to get answers and the fact that nature has all roots of therapeutics, efforts are made in the direction of finding those answers for providing ministrations for pancreatic cancer from plant products. Plant products are used as treatment options either directly in the form of extracts or an alternative to them is individual phytochemicals that are either isolated from the plants or are commercially synthesized for various purposes. In this review, we put forward such pharmacognostic initiatives made in combating pancreatic cancer, focusing mainly on plant extracts and various phytochemicals; along with the mechanisms which they triggered to fulfill the need for cytotoxicity to pancreatic cancer cells (in vitro and in vivo).
\end{abstract}

Conclusion: This study will thus provide insights into new combination therapy that can be used and also give a clue on which plant product and phytoconstituent can be used in dealing with pancreatic cancer.

Keywords: Pharmacognostic, Pancreatic cancer, Plant extract, Phytochemicals

\section{Highlights}

1. Lethality of pancreatic ductal adenocarcinoma (PDAC) with no full proof treatment process.

2. Plants in the PDAC treatment

3. Phytochemicals in PDAC treatment

\section{Background}

Pancreatic cancer (PC) is currently progressing to the second place in the list of deaths due to cancer and has a very low 5-year survival rate [1]. According to GLOBOCAN estimations for cancer incidence and mortality worldwide, around 185 countries PC have an incidence of cases as high as 45900 and deaths are almost the same

\footnotetext{
*Correspondence: kirankumar@curaj.ac.in

Department of Biochemistry, Central University of Rajasthan, $\mathrm{NH}-8$, Bandarsindri, Ajmer, Rajasthan 305817, India
}

as incidence, i.e., 432000 in both men and women [2]. PC is basically divided into two types; above $90 \%$ of the PC occurs in its exocrine portion and is termed as pancreatic ductal adenocarcinoma (PDAC) [3]. The other type of $\mathrm{PC}$ that occurs rarely is in the endocrine parts and called as pancreatic neuroendocrine tumors (pNETs); pNETs may be functional or non-functional, and to the surprise, $60-90 \%$ of them are non-functional and thus do not bother the patient as they remain mostly asymptomatic [4]. Of the different types of PC, PDAC is the most common as well as the most aggressive form [5]. PDAC has a dire prognosis process mainly contributed due to lack of diagnosis process and tools, screening of the disease, and also the major contributor is the restricted options available for treatment [6]. Patients with PDAC seldom reveal symptoms until it has reached its late stages; moreover, even in this stage, the

\section{Springer Open}

(C) The Author(s). 2021 Open Access This article is licensed under a Creative Commons Attribution 4.0 International License, which permits use, sharing, adaptation, distribution and reproduction in any medium or format, as long as you give appropriate credit to the original author(s) and the source, provide a link to the Creative Commons licence, and indicate if changes were made. The images or other third party material in this article are included in the article's Creative Commons licence, unless indicated otherwise in a credit line to the material. If material is not included in the article's Creative Commons licence and your intended use is not permitted by statutory regulation or exceeds the permitted use, you will need to obtain permission directly from the copyright holder. To view a copy of this licence, visit http://creativecommons.org/licenses/by/4.0/. 
symptoms develop slowly and not specifically indicating cancer including weight loss, exhaustion, jaundice, abdomen pain, and light-colored stools [7]. Owing to the late detection and metastasis of the disease surgical removal along with the chemotherapy or chemoradiotherapy is the best possible way of dealing the disease [8]. But due to the complexity and aggressive nature of PDAC, only $10-20 \%$ of patients at the time of diagnosis are suitable for undergoing surgery, and the remaining above $80 \%$ cannot receive the surgical treatment [9]. Despite surgery chemotherapy is a regimen consistently given in the treatment of PDAC, few chemotherapy drugs are used either alone or in combinations which include gemcitabine, nab-paclitaxel, 5-fluorouracil, oxaliplatin, irinotecan, and some others but those are even inefficient [10]. The above complications and no foolproof treatment options make the search for new therapies against PDAC a hotspot in research for scientists.

The search for reliable therapy agents against PDAC leads to a path of exploring innumerable compounds which could show the anticancer property; one such group of therapeutic agents which is well explored for other cancers and also that has proved itself effective are natural products especially the plant products [11]. The footsteps of the cures derived from plant products can be traced back to the base of all sorts of diseases $[12,13]$. Medication or therapy processes involving plant products are utilized by the majority of people all over the world as initial management of several forms of diseases [14]. Plant nutraceutical has obtained a crucial position in therapy due to the innumerable benefits that it provides to the well-being of a human [15]. The gift of therapeutic properties to plant products is attributed to the presence of biologically active compounds in them known as secondary metabolites $[16,17]$. These bioactive compounds provide the potential to the plant products to treat diseases like cancer by inhibiting tumor cytogenesis, by modifying the epigenetic processes, by suppressing or progressing gene initiation, by inhibiting cell proliferation, and a lot more [18-20].

Plant products used as drugs are less costly, highly efficient, non-toxic, obtained easily, and rarely cause any side effects [21, 22]. Also the medicinal plants are used to formulate the now used modern drugs that are effective against aggressive diseases $[19,23]$. Some examples of anti-cancer drugs that are derived from plants include docetaxel, paclitaxel, vinblastine, camptothecin, vincristine, and homoharringtonine which are applied in the treatment of cancers like breast cancer, stomach cancer, prostate cancer, ovarian cancer, lung cancer, Hodgkin's lymphoma, non-Hodgkin's lymphoma, brain cancer, testicular cancer, bladder cancer, melanoma, leukemia, thyroid cancer, neuroblastoma, multiple myeloma, chronic myeloid leukemia, and many more [24]. Of these drugs, paclitaxel is used in the treatment of PDAC. Many of the other drugs nearly about $60 \%$ that are used as chemotherapeutics against PDAC are also plantderived [25]. Moreover, plant products and their derived phytochemicals have proved to increase drug sensitivity in case of the resistance that occurs while the treatment process [26, 27]. Hence, these facts gave rise to more and more interest in searching for PDAC treatment in plant products and its phytochemicals. Therefore, this review emphasizes the plant products and phytochemicals used in the fight against PDAC in the hope of finding a sustainable solution to the persistent problem.

In the available literature, one could find studies describing the role of individual or specific phytochemicals or the phytochemicals of plants belonging to a specific family against pancreatic cancer and some reports focus on the effect of phytochemicals on stellate cells only; but none describe a group of phytochemicals as a whole. But this study one by one discusses about the different plants which were converted to crude extracts for application in treatment of PDAC. Further, the article moves on to the brief description of phytochemicals and also shows a short classification of those phytoconstituents. Later, the article gives a detailed explanation of the mechanistic changes that occur in the PDAC cells by the individual phytochemicals that are applied against them which leads to the cancer cell death and thus the reduction in tumor. In a section, we also show certain phytochemicals that are proved to show the effect on PDAC cells but their mechanistic details are not described in the different reports from where they are picked; giving an opportunity for the interested groups to identify certain phytochemicals whose mechanistic can be still explored, thus elaborately discussing the role of pharmacognostic studies against dealing with the deadly cancer PDAC. And showing the possibility of generating new therapeutics with lower toxicity and reduced side effects.

\section{Methodology}

The authors searched the National Center for Biotechnology Information (NCBI) PubMed database and Google Scholar. Different combinations of keywords such as plant extract(s), anticancer, pancreatic cancer, pancreatic ductal adenocarcinoma, phytoconstituent(s), and phytochemical(s) were used to find relevant research reports on the topic. Further, some more articles related to the review study were selected by analyzing the references of the articles found on PubMed and Google Scholar. Papers describing the use of plants in crude form or phytochemicals either isolated from plants or commercially purchased and used in the treatment of PDAC were picked up. All the relevant articles were thoroughly read and understood to get to the conclusions mentioned in the review. 


\section{Main text}

Plant products in the treatment of pancreatic cancer

Certain drugs used in the treatment of PDAC are plantderived which include docetaxel, paclitaxel, irinotecan, minnelide, and triptolide [28]. But these drugs were not developed specifically keeping in mind the behavior of PDAC and are used in various cancers; thus, these drugs can be seen to be highly toxic and less effective for PDAC patients [29]. Thus, giving way to the need of finding new drugs that are specifically designed to keep the PDAC tumor in view. For PDAC treatment, certain plant products have been displayed to minimize the chemoresistance of the tumor to modern drugs in their presence or pre-treatment, also some of them have been efficient in creating toxicity for the tumor and causing its death [30]. These useful effects of plant products further encourage researchers to find therapy options in natural products; Table 1 briefs certain plant extracts that were tested as treatments upon PDAC, and their mechanism of action and $\mathrm{IC}_{50}$ values is also shown.

Looking at the past decade of research on PDAC using plant extract, we see that a group of scientists from the USA screened different leaf extracts from various medicinal plants against PDAC cell line PANC-1, Capan-1, and Mia Paca-2; the plants belonged to families like Meliaceae, Burseraceae, Amaranthaceae, Rutaceae, Solanaceae, Euphorbiaceae, and Combretaceae. Interestingly, some extracts belonging to the same family were found to be acting differently on the cell lines which give a clue that the difference might be due to dissimilar ways of extraction which lead to the presence of different compounds in the extract. The extracts that were concluded to be most effective in their study were all methanol extracts or fractions of methanol extract which give a strong clue that compounds in methanol extracts have higher anticancer potential than compounds in other extracts [56]. Similarly, supporting the efficacy of methanol extract another group of scientists from the USA and India worked on another plant Achyranthes aspera, they proved that methanol extract of leaves of this plant showed high toxicity to PDAC cell lines and extremely low cytotoxicity to normal cell lines. Moreover, they separated fractions from the crude extract and concluded after testes that the fraction containing a higher amount of polar molecules that dissolve in moderately polar chemical like methanol are responsible for cytotoxic behavior they also found that these compounds are insoluble in polar solvents like water and non-polar solvents like chloroform [57]. The same group of scientists carried their work forward and showed the effects of the extract on athymic hairless mice and proved it to be reducing pancreatic tumor in them via apoptosis, giving a lead candidate to be developed into a drug against cancer [58].
Opposite to the abovementioned findings, some other scientists showed that aqueous root extract of dandelion induced death in PDAC cell lines; they confirmed their findings by initial screening of cell viability by WST-1 assay and further showed it to be death induced by apoptosis. The apoptotic death was examined by Hoechst staining and Annexin- $\mathrm{V}$ binding assay that showed both the pathways of apoptosis, i.e., intrinsic and extrinsic were activated causing destabilization of mitochondrial membrane shown by mitochondrial membrane potential assay, destabilization ultimately leads to death of mitochondria. This mitochondrial death activated autophagy in the cells due to stress conditions build up because of the damage; in the presence of the extract, the stress conditions were prolonged and this caused the cells to enter death due to autophagy which was revealed by conversion of LC3-I to LC3-II after treatment. But at the same time, it was seen that the extract concentration, i.e., $5 \mathrm{mg} / \mathrm{ml}$ that showed $50 \%$ cell in PDAC cell lines in $48 \mathrm{~h}$ did not show any changes in normal cell lines even up to $96 \mathrm{~h}$ which verified that the extract kills cancer cells and not normal cells [59]. This study had a drawback that it did not identify the individual component present in the extract responsible for the PDAC death, leaving possibilities indicating that not only components of methanol extract but also aqueous extract can show cytotoxic effects, which all depends on the type of phytoconstituents present in the plant tested and the fact that in which type of extract those components are isolated to equip the extract with anticancer properties.

Another research aiding the fact of the aqueous extract being cytotoxic to PDAC cells was conducted by a group of scientists from Israel; they worked on 3 different PDAC cell lines that are Panc-1, COLO-357, and p34 and tested the efficacy of well-known hub of therapeutics, i.e., the aqueous leaf extract of Moringa oleifera against these cell lines by XTT cell survival assay; also they confirmed the effect of treatment on cell cycle by flow cytometry analysis and protein evaluations by immunoblotting confirmed the pathway by which the extract was inducing death. Their study concluded that this extract induced apoptosis among the cell lines via downregulation of NF- $\mathrm{B}$ signaling. Even though they did not isolate individual compounds from the extract but from the literature, they picked certain compounds present in the extract that may be responsible for the anticancer property, and those compounds include flavonoid pigments, glycosides, isothiocyanates, glucosinolates, glycerol-1-(9-octadecanoate), beta-sitosterol, beta-sitosterol-3-O-beta-D-glucopyranoside and 3-O(6'-O-oleoyl-beta-D-glucopyranosyl); further, they also showed that this extract has synergistic effects when used along with cisplatin against Panc-1 cells and thus 


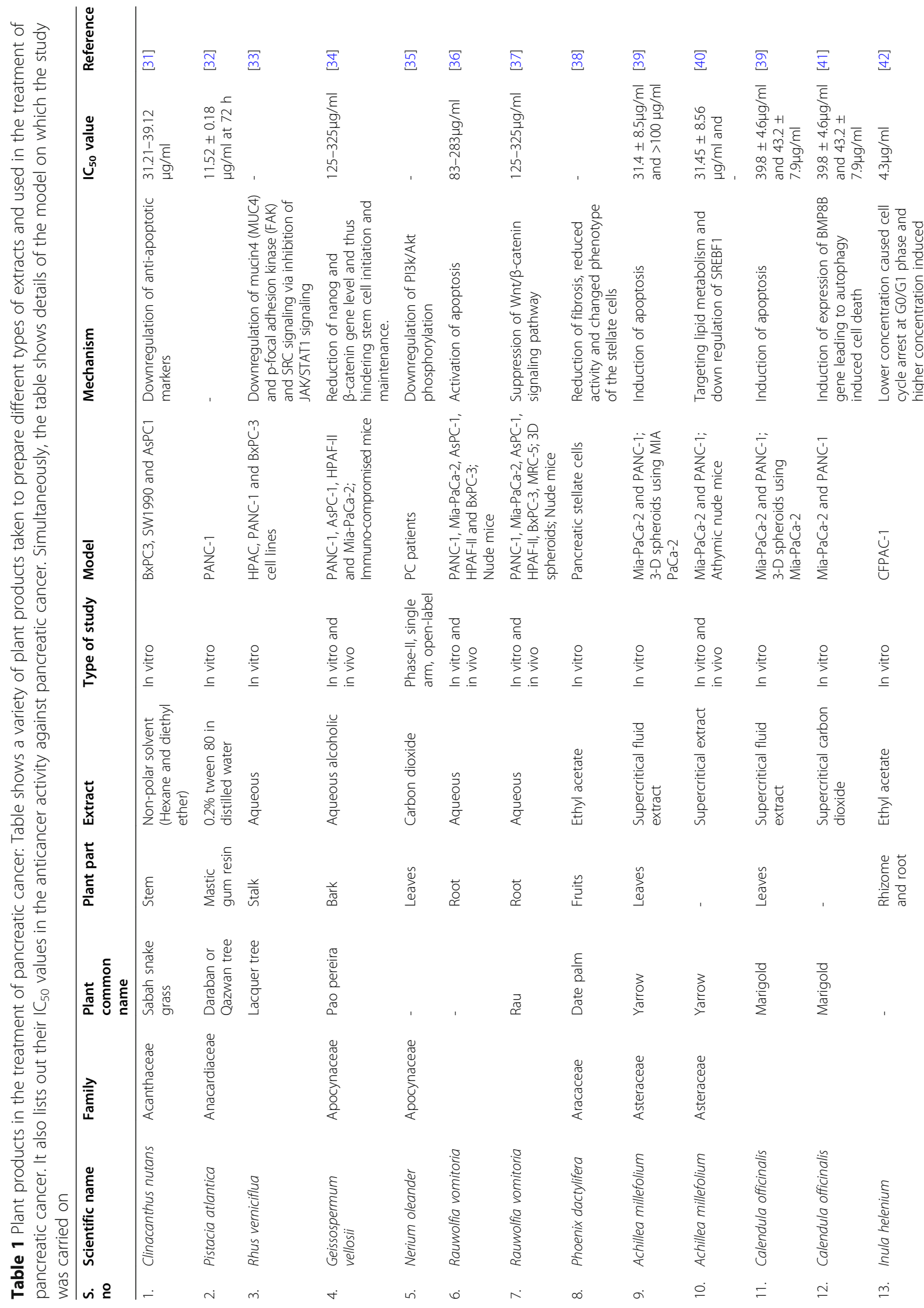




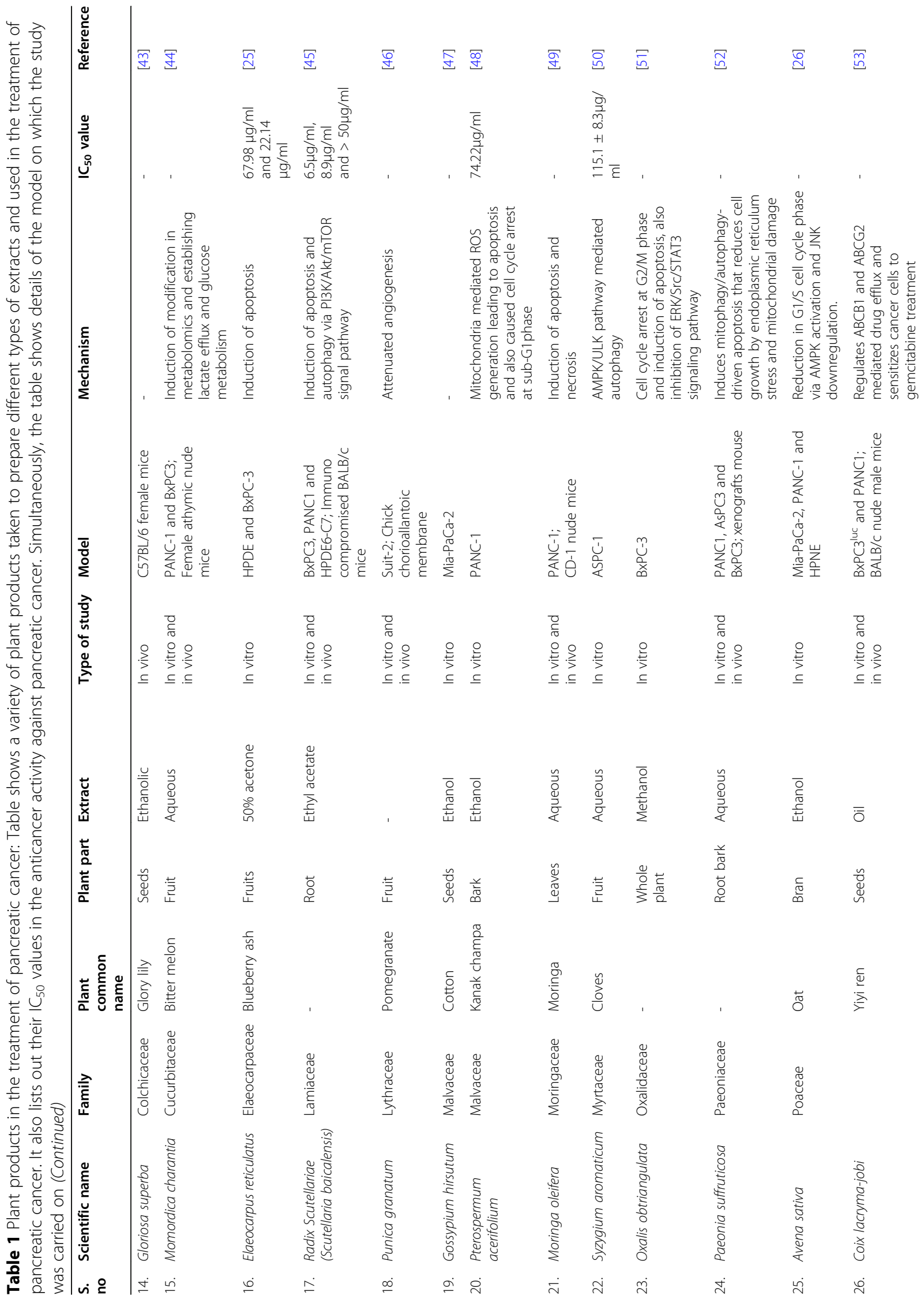




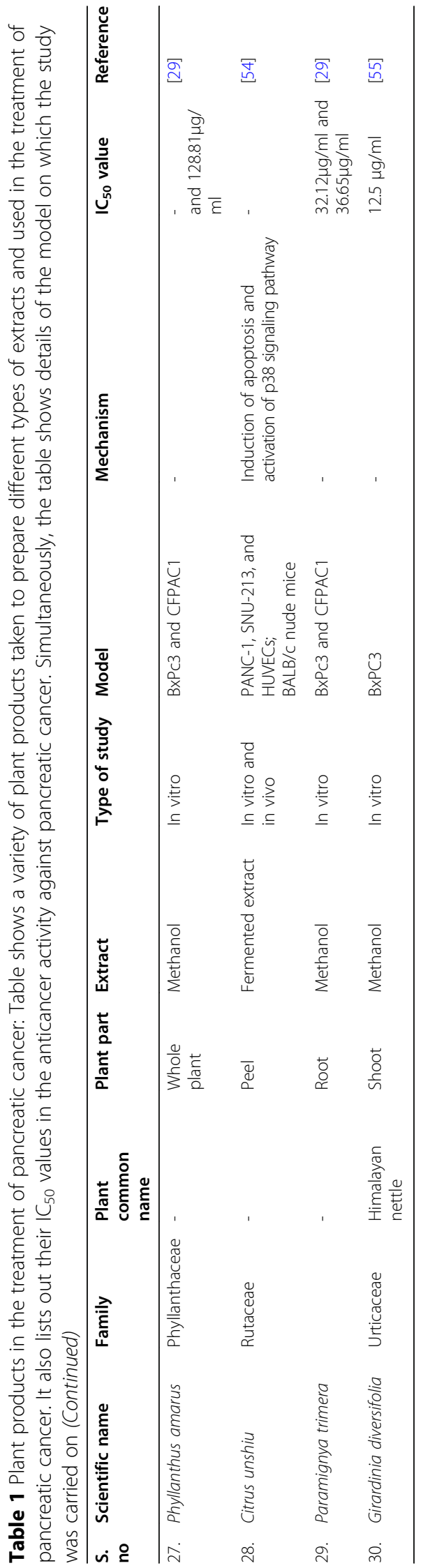


enhances the efficiency of chemotherapy used for treating PC [60]. Some more scientists from the USA performed an experiment using aqueous fruit juice of Momordica charantia as a treatment for PDAC cell lines BxPC-3, Mia-Paca-2, AsPC-1, and Capan-2; the effect of the juice on the cell survival was evaluated by MTT assay which showed it to be effective in killing the cancerous cells. Further, the DNA fragmentation assay gave a hint that the death was caused by activation of apoptosis which was then confirmed by annexin V/propidium iodide staining; from immunoblotting assay carried to check the release of cytochrome-c from mitochondria to cytosol, it was found that there was a release of cytochrome-c to cytosol showing that intrinsic apoptotic pathway was activated which also caused mitochondrial damage. Next, to show the other pathways affected tests were done to analyze AMPK pathway because it is a pathway activated due to damage of mitochondria that leads to a reduction in levels of ATP/AMP ratio and from tests, it was proved that AMPK pathway was activated due to the presence of the juice, which shows a connected role of apoptosis and AMPK pathway in cytotoxicity against PDAC. Similar effects were seen in vivo in nude mice due to the presence of the juice suggesting it to be effective in the reduction of PDAC and increase in survival. These scientists also found the presence of cucurbitane triterpenoids in the juice which are known for their anticancer potential, four different types of triterpenes, i.e., momordicine I, momordicine II, kuguaglycoside G, and cucurbitacin I were analyzed by them which could be possibly the agents responsible for the cytotoxic effect of juice on PDAC cells; moreover, these cucurbitane triterpenoids were earlier reported to be inducing apoptosis and also activating AMPK pathway which was in accordance with the findings of the study [61], thus giving a lead of triterpenes be the responsible agents of treatment of PDAC.

Further, some more scientists conducted their research using aqueous extract, ethanolic extract, and essential oil of Ocimum sanctum against PDAC cells. Their studies suggested that ethanolic extract proved best in the invitro experiments by causing cytotoxicity, inducing apoptosis, and reducing invasion and migration in PDAC cell lines; at the same time, the aqueous extract was not so effective in the in vitro experiments and was $20-40$ folds less effective as compared to the ethanolic extract, and in case of essential oil, they found it was effectively causing cytotoxicity and inducing apoptosis but was unable to reduce invasion and migration of the cells rather it increased them; these findings suggested them to use ethanolic extracts for the in vivo tests. But to their surprise, they found the ethanolic extract to be intoxicating the mice in the doses required for the treatment, hence they switched to aqueous extracts which is reported for other cancer treatment in vivo and found that the aqueous extract in vivo increase pro-apoptotic genes and reduced genes that supported proliferation and migration of PDAC [30]. These variations in the results suggested that each extract acts differently in vitro and in vivo depending on their bioactive compounds and the environment that they are subjected to for their action, which gives direction to the importance of isolation of bioactive substances from the crude extracts and testing of their anticancer potential. To check on the difference between methanolic and aqueous extract, a team of scientists compared methanolic and aqueous extract of the whole plant of Euphorbia tirucalli for its phytochemical content; they found that the total phenolic content of the methanolic extract was higher and almost double the amount present in aqueous extract, but on individual component analysis, they found flavonoids to be higher in aqueous extract than methanolic extract and the proanthocyanidins were present in almost equal amounts which clearly showed the difference in the phytoconstituents of the two extracts. To their surprise when they checked both the extracts on PDAC cell line Mia-Paca-2 they found both of them killing $~ 50 \%$ of cells at $50 \mu \mathrm{g} / \mathrm{ml}$ which lead to a thought that there are certain other components present in the extracts that give them the cytotoxicity potential which needs to be evaluated and understood [62]. A different type of mechanism of death, i.e., autosis was seen to be triggered in PDAC cell lines due to ethanolic ginger extracts. Upon treatment of PDAC cells initially, it was found that the treatment caused an arrest in $G_{0} / G_{1}$ cell cycle phase and later cell death stages, it was found to cause plasma membrane rupture and nuclear shrinkage but such behavior of nucleus was rarely seen during apoptosis, further tests including the annexin $\mathrm{V} /$ propidium iodide staining and mitochondrial membrane potential suggested apoptosis but the absence of nuclei fragmentation process and no increase in subG ${ }_{1}$ fraction did not allow complete confirmation of apoptosis. Moreover, on checking factors involved in mitochondrial independent cell death and necrosis, it was concluded that the treatment is causing neither death by the mitochondrial independent path and nor by necrosis. Further investigations diverted the chances of death to be due to autophagy due to the increase of LC3 II/ LC3 I ratio and other autophagy-activated pathways, but to a surprise, upon testing with autophagy inhibitors, the death was inhibited partially. Finally, with the help of TEM analysis, it was seen that mitochondria were electron-dense, focal perinuclear swelling was seen, and vacuoles were empty; these findings which suggested caspase-independent but autophagy-like death lead to conclusions that the death 
was due to autosis. Further when tested in vivo on mice, the extract showed tumor suppression along with the increase in survival with no serious side effects and abnormalities due to extract treatment [63].

Another interesting and not commonly used extract is a supercritical carbon-dioxide extract. A team of different scientists from the USA used such an extract of Nerium oleander leaves against PDAC; this supercritical carbon-dioxide extract is named PBI-05204 and has proved its efficacy against PC at the clinical phase-I level of trails. In 2015, the scientists have put forward the effects of PBI-05204 in an orthotopic mouse model. They showed that this extract not only reduces the tumor in the models but also has the capacity to completely eradicate it at higher doses. They found that PBI-05204 is effective even as a monotherapy and prevents tumor growth by affecting the $\mathrm{PI} 3 \mathrm{k} / \mathrm{mTOR}$ pathway and that too without showing any cardiac toxicity. These data from the orthotopic models added to the potential of PBI-05204 to act well in combating PC and safe for moving to the phase-II trials [64]. This study was definitely a leap forward as the phase-II trails were conducted. This phase-II study enrolled 42 patients out of which 38 were analyzed, and the primary endpoint of the trial was overall survival which was unfortunately not reached but fruitfully showed signs of improvement in the pre-treated patients. In addition, the scientists claimed that the trial was not conducted for monotherapy by PBI-05204, and therefore, further trials are to be carried to completely understanding the mode of action of PBI-05204 [35].

Even when certain candidates reached the human trials to get their efficiencies checked for PDAC, the search for more potent and beneficial compounds did not stop or got hampered. Moreover, even if the extracts that reached the trials were not commonly used extracts, the search for efficient therapeutics in the common type of extracts continued. A team of scientists checked three different extracts of Olea europaea leaves, i.e., water, $50 \%$ methanol, and 50\% ethanol extract. The scientists suspected phenolic compounds especially oleuropein present in plenty in the plant to be effective against the PDAC as the compound is proven to act against several other cancers. When they checked the phytochemical content of the three extracts, they found oleuropein to be present in higher amounts in 50\% methanol and 50\% ethanol extracts as compared to the aqueous extract, but the total phenolic content of all the three extracts was similar. Upon testing for the anticancer potential against the PDAC cell line Mia-Paca-2, they found water extracts to be most effective, which made them conclude that other compounds present in the extract along with oleuropein might be responsible for the anticancer activity and thus increased the need to check the individual compound so as to get to a better conclusion of the compound causing the death of PDAC cells [65]. To add to the search of anticancer compounds against PDAC, scientists from Vietnam and Australia reported activity of methanolic root extract of Paramignya trimera against different types of cancers including PDAC. They initially performed phytochemical analysis on the crude extract and then using HPLC separated four major components in different fractions out of the crude extract. When they checked these crude extracts and their fractions, they found them to exert good antioxidant activity and cytotoxicity on all cancer cell lines especially on PDAC cell lines. But to their surprise, they found the crude extract to be more effective than the isolated fractions indicating that not the major components but may be certain minor components present in the crude extract are responsible for the high cytotoxicity of the crude extract which gave a direction to check not only the major components of an extract but also the minor components which could be more advantageous [66].

The same group of scientists also checked for methanolic leaf extract of Paramignya trimera against various cancers and found it to be most effective against PDAC; further, they included more number of different PDAC cell lines to cross confirm their findings. And they found the extract to be very efficient against all types of cells, thus can act as a potential drug. They also found the extract to be rich in saponins which could have contributed to its anticancer effect, but it required the separation of those saponins to experimentally prove the hypothesis put forward [28]. The same scientists tested another plant for its effect on cancer cells including PDAC cells Mia-Paca-2. They made aqueous and methanolic extracts of Phyllanthus amarus whole plant to compare both the type of extracts for their activity. Upon phytochemical analysis, they tested that the methanol extract has higher amounts of saponins, flavonoids, proanthocyanidins, and phenols than the aqueous extract. Moreover, they isolated fractions of major phytoconstituents detected in HPLC analysis. Upon cytotoxicity analysis, it was seen that methanol extract at $100 \mu \mathrm{g} / \mathrm{ml}$ exerted $48 \pm 3 \%$ growth inhibition in PDAC cells while at the same concentration aqueous extract showed $38 \pm 5 \%$ growth inhibition indicating methanol extract to be more toxic, but as in their previous study in this study, they found the crude extract to be more potent than the isolated fractions of the major components giving support to their previous findings of minor components being responsible for cytotoxicity; however, the minor components were not isolated for confirmation and conclusion of the hypothesis [67].

The next approach was a combination treatment against nitrosamine-induced PDAC in the rats, but interestingly, the combination was not set up using a synthetic 
or modern drug, rather it was of an aqueous leaf extract from two medicinal plants, i.e., Momordica charantia and Ocimum basilicum. During the experiment, the rats were administered various doses of the extract to the stomach, i.e., intragastrically along with a fixed dose of nitrosamine and the effects of it on the tumor were examined; as a result, the scientists found that the extract had capacity to fight against-induced PDAC. The mechanistic analysis showed that the extracts decreased the damage caused to Kras gene due to the administration of nitrosamine which resulted in the reduction of tumor. The qualitative phytochemical analysis of the extract revealed the presence of flavonoids, saponins, tannins, alkaloids, and glycosides; among which tannins were considered to be showing the anticancer activity against PDAC, but this consideration still lacks experimental proofs [68]. But experimental proofs were given for high anticancer potential of saponin-enriched butanol fraction of crude leaf and stem extract of Helicteres hirsuta as compared to the crude extract itself and its aqueous fraction. Both the leaf and stem saponin-enriched butanol fractions were seen to be very potent causing death in vitro in different PDAC cell lines with an $\mathrm{IC}_{50}$ value in the range of $1.80-6.43 \mu \mathrm{g} / \mathrm{ml}$, whereas for aqueous fractions, it was above $200 \mu \mathrm{g} / \mathrm{ml}$ and for crude extract, it was $18 \pm 1.5 \mu \mathrm{g} / \mathrm{ml}$ of stem extract and $47.61 \pm 2.3 \mu \mathrm{g} / \mathrm{ml}$ of leaf extract. From these results obtained by MTT and CCK- 8 assays, it is very clear that the saponins are involved in the anticancer activity of Helicteres hirsuta which further requires molecular analysis to know its mechanism [69].

When attempts are made in searching therapeutics for PDAC treatment, some researchers also picked plants that have not been yet checked for their cytotoxic effects on any type of cancer cells but are well known for their therapeutic effect in Indian traditional medicine. These researchers made an ethanol extract of Pterospermum acerifolium bark and tested its effect on PDAC cell line by MTT assay which showed that the extract had an $\mathrm{IC}_{50}$ value of $74.22 \mu \mathrm{g} / \mathrm{ml}$ on Panc- 1 cells. Further, they found the extract to reduce the migration ability of the cancer cells by scratch assay and showed using DAPI staining assay that the treatment caused nuclear condensation and damage, and with acridine orange/ethidium bromide staining process, they confirmed apoptosis being the cause of death. When reasons for apoptosis induction were checked, it was concluded that the treatment caused mitochondrial membrane damage that leads to high levels of ROS generation that resulted in triggering of apoptosis and ultimately death of the cancer cells [48]. While experiments were conducted to explore all unknown compounds, some scientists choose to check the well-known anticancer compounds present in plenty amount in particular extracts. The plant used is a well-known medicinal herb Inula helenium and compounds are sesquiterpene lactones. For the extraction of these compounds, the roots of the plant were subjected to ethanol and ethyl acetate to ultimately produce ethyl acetate extract rich in sesquiterpene lactones which contain three main components alantolactone, isoalantolactone, and alloalantolactone confirmed by NMR studies. When checked against PDAC cell line CFPAC-1, it was found that the ethyl acetate extract of Inula helenium was able to cause cytotoxicity in the cells with $\mathrm{IC}_{50}$ value $4.3 \pm 1.1 \mu \mathrm{g} / \mathrm{ml}$; at the low concentrations, the extract induced cell cycle arrest at $G_{0} / G_{1}$ stage as showed by propidium iodide staining and flow cytometry analysis. But when subjected to higher doses of extract, the cells were seen to die due to mitochondriadependent apoptosis. For further exploration of involved mechanisms, the team took up the fact that CFPAC-1 cells carry allelic deletion of SMAD4 gene, and thus, inactivation of SMAD4 protein which affects further phosphorylation mechanisms of different pathways that provides chemoresistance to the cells. One such pathway altered in CFPAC-1 is STAT3/AKT pathway, upon treatment with the extract it was seen that the downregulation of phosphorylation of STAT3 and AKT occurred which causes a reduction in migration or invasion and could be the reason for effect on mitochondria leading to apoptosis but requires further investigation [42].

Yet, another experiment was conducted that showed regulation of STAT proteins in the treatment processes of PDAC. Aqueous extract of allergen removed Rhus verniciflua was used for treating invasive and metastatic PDAC. The initial experiments of migration and invasion proved that the extract was capable of reducing the invasion and migration processes. It is known that one of the reasons for the invasive and metastatic nature of PDAC is activation and upregulation of STAT1 via interferon $\gamma$, and the extract reduced this invasive nature, thus giving a clue that it possibly in some way affects this pathway. The analysis of MMP9 levels after treatment with the extract gave support to this hypothesis and put forward the inhibition of STAT1 to be the reason behind the inhibition of invasion and metastasis. When the involvement of STAT1 was confirmed, another protein that came into the picture was MUC4 which is regulated by STAT1 and STAT3 that in turn adds on to the mobility and invasive nature and also promotes chemoresistance in PDAC via providing resistance to apoptosis process. Upon checking for MUC4 protein, it was demonstrated that the MUC4 expression was reduced along with the reduction in expression of anti-apoptotic genes and upregulation of pro-apoptotic genes. Moreover, treatment with this extract also showed a reduction in phosphorylation of FAK gene that is involved along with STAT1 and is associated with cell adhesion and spreading. Thus, overall, it was seen that 
the Rhus verniciflua extract reduced the aggressive PDAC via MUC4 downregulation involving STAT1 and FAK which could be a lead to develop a treatment against chemoresistance in PDAC [33]. Even though the mechanism of action of the extract was described in this study, the individual component of the extract causing these changes was still to be identified as the crude extract can show variability in results when subjected to in vivo models.

Supporting the fact that there is a presence of another pathway that reduced PDAC growth some researchers gave a treatment of aqueous extract of Paeonia suffruticosa to different PDAC cell lines. By conducting various experiments including MTT assay, western blotting, immunofluorescence assays, colorimetric assays, fluorescenceactivated cell sorting assay, trans-well migration assay, and xenograft model study the team showed that the treatment of extract caused accumulation of ROS in PDAC cells causing endoplasmic reticulum stress that triggered autophagy/mitophagy due to imbalance in mitochondrial membrane potential. This autophagy/mitophagy induced apoptosis via intrinsic and extrinsic pathways in PDAC cells. Also the extract was seen to reduce the cell cycle progression by downregulation of CDK and decreased mobility of PDAC cells via alternations in the actin cytoskeleton dynamics. Moreover, in the PDAC xenograft mouse models the extracts when administered orally, with or without a combination of gemcitabine, it was seen to reduce the tumor growth while having no effect on the weight of the mouse and with no adverse side-effects. Conversely, while the crude extract showed such beneficial results against PDAC some of the isolated compounds when tested did not show such good effects indicating the necessity of checking the individual components of the extracts thoroughly to get to know exactly which components give such good effects against PDAC [52].

An attempt was done by Mouhid et al. by putting forward a comparative analysis between the effect of a leaf extract from 4 plants belonging to 2 different families and taking 2 different types of extract for each plant. The plants were Melissa officinalis and Origanum majorana of family Lamiaceae and Achillea millefolium and Calendula officinalis from the family Asteraceae extracts prepared were supercritical carbon-dioxide extract and ultrasonic-assisted extraction. These extracts were checked on PDAC cell lines Mia Paca-2 and Panc-1. Initially, all plants were checked on Mia Paca-2 and the results showed that the extracts from plants of Asteraceae were more effective and that of Lamiaceae did not induce death of cancer cells. Further, when evaluated on Panc-1 cell lines, it was found that only the supercritical carbon dioxide extract was able to kill cells and not the ultrasonic-assisted extract. This clearly indicated the difference in bioactive compounds to be responsible for the difference in the activity. Further experimentation revealed that the cytotoxicity was occurring due to the induction of apoptosis via cleavage if caspase $3 / 7$; moreover, the extracts interfered with the process of colony formation in the 3D sphere models and also showed synergistic effect along with the chemotherapy drug 5fluorouracil which showed a way to create a plant-based treatment along with the modern chemotherapy to control the growth and threat of PDAC [39].

Carrying the work forward, these scientists performed microarray gene expression analysis on the Achillea millefolium extract-treated PDAC cell lines to identify the direct targets of the extract. They found Sterol Regulatory Element Binding Transcription Factor1 (SREBF1) to be directly targeted by the extract in both the tested cell lines. SREBF1 is highly expressed in PDAC cells but not in normal pancreatic cells; the high expression of SREBF1 factor causes the poorest prognosis of PDAC and also this factor provides an ability of high invasion and metastasis. SREBF1 being the direct target of the extract and the presence of this factor in cancer cells and not in normal cells gives an explanation for the effect of the extract only on cancer cells and not normal cells. SREBF1 has been proved to increase the oncogenic nature by lipogenesis caused due to increase in Fatty Acid Synthase (FASN) and Stearoyl-CoA Desaturase (SCD), and in this study, the scientists found that after treatment with the extract, the levels of FASN and SCD were decreased. Due to the decrease in FASN and SCD at both transcriptional and post-transcriptional levels, there were effects in the PDAC cells, and due to the downregulation of FASN, the PDAC cells become more sensitive to chemotherapy drugs and due to the SCD downregulation, the cell proliferation and survival of PDAC cells are also reduced, thus giving strong evidence that crude extracts can have multiple targets and different ways to accomplish their target of PDAC reduction. Also in the xenograft models, the tumor growth was seen to be reduced due to the treatment with the extract and the reduction was facilitated partially due to downregulation of SREBF1, thus suggesting further investigation on the mechanisms that reduce the PDAC growth in vivo [40].

As seen in the abovementioned, study plant extracts can reduce chemoresistance by targeting factors that support the resistance. One such study showed that ethanol extract of Avena sativa bran can affect the survival of gemcitabine-resistant PDAC cells. Upon initial treatment of PDAC cells with the extract, it was noted that the extract can reduce cell viability and also reduce the colony formation in the cancer cells but did not affect the normal cells. Further experiments on cell cycle progression revealed that the treatment with extract caused cell cycle arrest at $G_{0} / G_{1}$ phase, thus reducing 
cell proliferation and analysis using TUNEL assay and annexin V/propidium iodide staining, and apoptotic death due to treatment was confirmed. Mechanistic study of apoptosis showed induction of apoptosis occurred due to cleavage of caspase- 3 and PARP and simultaneous reduction in Bcl-2 expression. As it was seen that treatment reduced cell proliferation and apoptosis, it was hypothesized from the literature that AMPK and JNK pathways are involved; thus, this pathway was checked and results showed increased phosphorylation of AMPK and decreased phosphorylation of JNK which confirmed that cell death was because of AMPK/JNK facilitated apoptosis. AMPK is also known for its effects on activation of autophagy, but when autophagy markers were tested, it came out that autophagy was not induced, rather only apoptosis was occurring. The main objective of the study was to check the effect of the extract on drug-resistant PDAC cells, and when it was checked on the gemcitabine resistant Mia-Paca-2 cells, they found that the extract treatment significantly reduced levels of RRM1 and RRM2 both of which are enzymes present in PDAC patients and help in the repair of DNA damage caused due to gemcitabine in PDAC cells, thus making them resistant to gemcitabine treatment. Thus, due to this effect when the extract was given in combination of gemcitabine, it showed a synergistic effect in killing the PDAC cells. Even though the individual component of the extract causing reduction in PDAC growth was not isolated, the literature showed avenacoside $\mathrm{A}$ to be a component to kill other cancers by inducing apoptosis and reducing cell proliferation and in the ethanol extract avenacoside A was present, hence increasing the need to test the isolated compound for its effect on PDAC treatment [26].

Many times, it is considered that autophagy and apoptosis are interrelated and act synergistically, but it is not entirely correct, at times autophagy and apoptosis act in an antagonist manner. One such proof of this phenomenon was given by some researchers who made a total flavonoid aglycones extract of Scutellaria baicalensis using ethyl acetate. They checked this extract on PDAC cell lines and found it to be cytotoxic at $\mathrm{IC}_{50}$ value of 41.7 and $47.4 \mu \mathrm{g} / \mathrm{ml}$ for BxPC3 and Panc1, respectively. They found the extract to induce apoptosis in the cells via activation of caspase signaling pathway, also the extract induced autophagy by inhibition of $\mathrm{PI}_{3} \mathrm{~K} /$ Akt/mTOR pathway. But when they checked for the link between the autophagy and apoptosis pathways, they concluded that inhibition of autophagy intensely increased the apoptosis percentage demonstrating that autophagy in this case acts as tumor protective mechanism against treatment-induced apoptosis. When checked in vivo in the xenograft mice model, it was seen that due to treatment tumor growth was suppressed but as seen in in vitro models, both apoptosis and autophagy were activated, thus giving a clue that in such cases of antagonist autophagy and apoptosis use of autophagy inhibitor along with the treatment can further improve the treatment processes, and because of such occurrences, it becomes important to clearly know the role of each mechanism in the treatment process [45]. The aqueous leaf extract of Moringa oleifera was again checked by some scientists for its activity against PDAC; the difference in their studies was the previous one highlighted the effect of extract and in combination with the chemotherapy drug, while in this study, the researchers bring into light the effect of the presence of extract when given in combination with radiotherapy; moreover, in the later study, the researchers gave a chemical analysis of the aqueous extract using gas chromatography technique which could help identify individual compounds. Radiotherapy was brought into light because even being a widely used technique in various cancers, this technique is not established in case of PDAC treatment and still requires improvements. From their results, the extract was effective alone, and in combination, the inhibition of cancer growth and development both in vitro and in vivo was achieved to a greater extent, thus giving an evidence that the radioresistance in PDAC can be reduced by using an aqueous extract of Moringa oleifera, and opening new ways for studying the individual components of the extract for the defined activities, it showed in combating PDAC [49].

As PDAC possesses very peculiar and unlike characteristics when compared to other cancers, some scientists hypothesized and put forward the use of a plant Oxalis obtriangulata which is well known for its therapeutics in other types of diseases but is not much known for its anti-cancer potential. They prepared methanol extracts of the plant and tested against PDAC cells for their cytotoxic effect by MTT and antiproliferation effect by colony formation assay, in both cases after treatment, it was seen that the extract caused cytotoxicity and also reduced cell proliferation. Upon validation of cell proliferation reduction, the phase at which the proliferation ceased was checked by flow cytometry assay that showed cell cycle arrest at $G_{2} / M$ phase, and further, by FACS, it was proved that the treatment caused apoptosis. The occurrence of apoptosis, cell cycle arrest, and reduced cell proliferation indicated the involvement of STAT3 as this signaling molecule is involved in all the mentioned processes of cancer cells. And on western blotting analysis, it was found that treatment with the extract caused inhibition in the expression of phosphorylated Src, phosphorylated ERK, and phosphorylated STAT3 along with reduced nuclear translocation of STAT3 and thus also affected other downstream genes that helped in the survival of the PDAC tumor. Thus, these results showed 
that plants which are not established for anti-cancer activities can also show an effect in reduction of PDAC and can act as a therapeutic, but it requires further detailed investigation on its mode of action and components involved [51].

Another such less explored fruit was experimented for its response on PDAC cells, i.e., fruit of Elaeocarpus reticulatus, a $50 \%$ acetone extract of the fruit was prepared for the experiments. Additionally along with the crude extract, fractions of the extract were also prepared using HPLC and those were also checked on PDAC cells; one major component was cucurbitacin I which was also experimented separately. In the experimentation, it was found that the crude extract caused a reduction in cell viability of PDAC cell line $\mathrm{BxPC} 3$ at an $\mathrm{IC}_{50}$ value of $22.14 \mu \mathrm{g} / \mathrm{ml}$, but it did not significantly reduced the viability of CFPAC-1 cells, thus showing a selective effect also the extract did not affect the normal pancreatic cells and showed an $\mathrm{IC}_{50}$ of $67.98 \mu \mathrm{g} / \mathrm{ml}$ for HPDE cells. Further analysis showed that the treatment with extract caused apoptosis in a caspase-dependent manner but did not induce cell cycle arrest. However, the fractions from the extract were not effective in reducing the cell viability of the PDAC cells and hence showing no anticancer effect, while cucurbitacin I decreased PDAC viability even in low concentrations and also did not show selectivity as shown by the crude extract. These results suggest that there are compounds in the extract that act very differently on the PDAC cells that need extensive studies to be understood clearly [25].

From the above papers, we came across plants whose crude extracts were effective against PDAC, but still need further investigation to be approved for being used as treatment. The plants belonged to different families and different processes of extraction were used; the different families of the above plants are shown in Fig. 1. Out of the various extraction processes, methanol and aqueous extracts were seen to be widely used and most effective against PDAC but also the beneficial effects of other extracts cannot be neglected, thus indicating towards the necessity of the individual study of compounds found in these extracts which can be potentiated candidates for the drug development for the treatment of PDAC either as monotherapy or in combination. Also in some studies, we come across the findings that the fractions were not as efficient as the crude extracts and

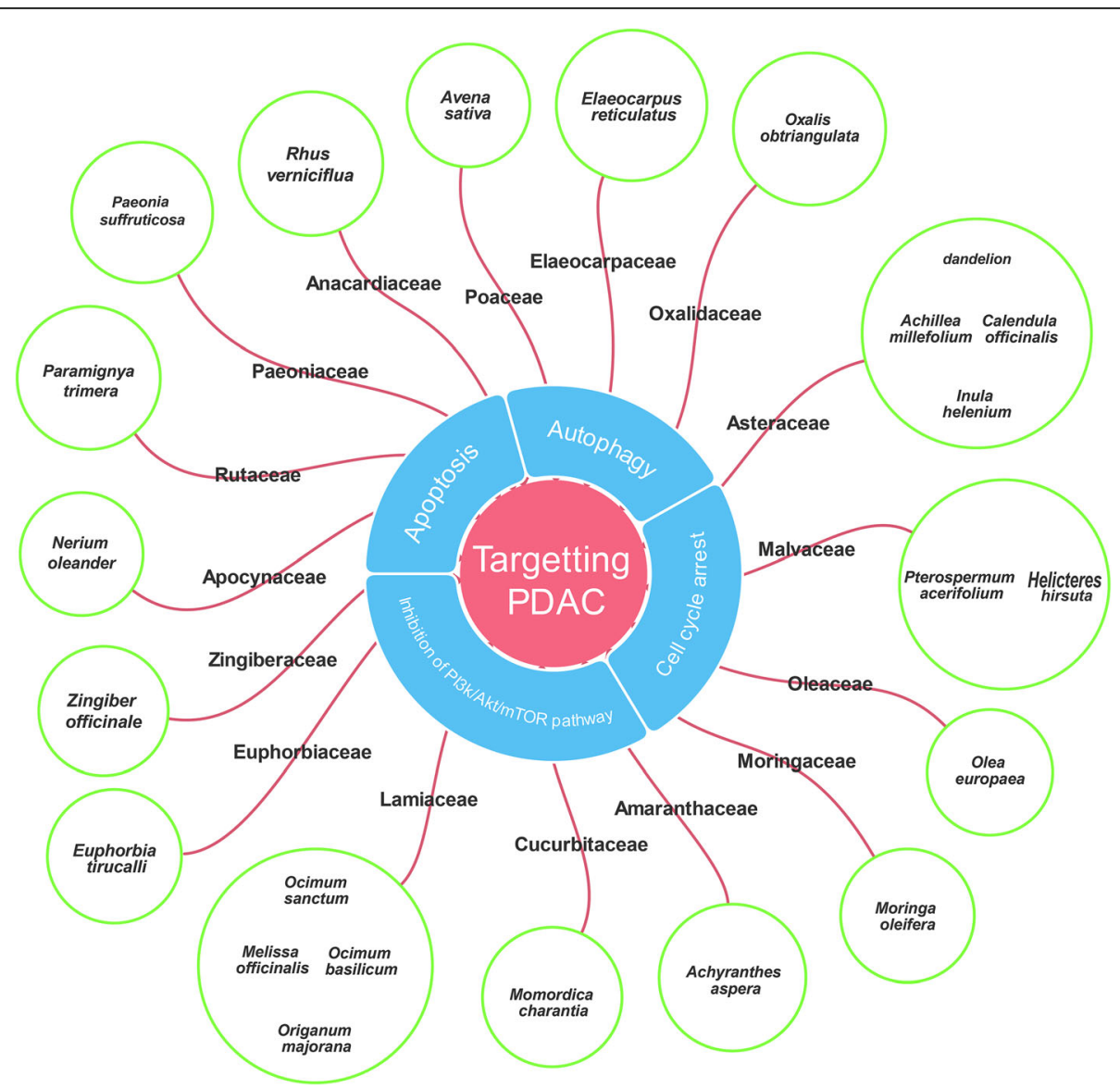

Fig. 1 Figure shows the different families of plants and the examples of the plants in that family that are being used in targeting PDAC 
also the major components did not behave likewise as the crude extract which increases the possibilities that the components present are working in an interrelated manner where the presence or absence of one compound affects the activity of the other compound, and another conclusion that can be drawn is not always the major components present in an extract are responsible for its entire activity and potentiality. Even when many extracts are tested to find a cure for PDAC, there are many plants whose extracts are used for the treatment of different cancers, and thus, they can be checked on PDAC cells to know their effect on them. Some of such examples include Acacia saligna, Lawsonia inermis, Parthenium hysterophorus, Lagerstroemia speciosa, Byrsocarpus coccineus, Mangifera indica, Annona atemoya, Centella asiatica, Abrus precatorius, Boswellia serrata, Plumbago zeylanica, Catharanthus roseus, Solanum aculeastrum, Tinospora cordifolia, and Tecoma stans.

\section{Phytochemicals in cancer}

Phytochemicals have proved to be helpful in the reduction of cancer risk, and a cancer prevention strategy can also be made keeping phytochemicals as the key components [70]. Even there are case study reports that show if phytochemicals are consumed in higher amounts in the diet, they reduce the incidence of various types of cancers, PDAC being one of them [71]. These phytoconstituents are recommended for having anti-cancer potential and have importance due to their low toxicity and greater diversity [72]. Phytochemicals show diverse ways in which they deal with the cancer cells and cause their death, thus fulfilling the need for treatment options [73]. Phytochemicals have also shown to increase the effect of classical drugs and reduce their toxicity and also make the cancer cells sensitive to the drugs for which they have developed resistance [74]. Various types of phytochemicals are being tested on PDAC (Fig. 2); some of which also have a good effect in combination therapy. Table 2 shows certain phytochemicals tested against PDAC and also shows their $\mathrm{IC}_{50}$ values and the types of models on which they were tested.

\section{Pathways triggered by phytochemicals in pancreatic cancer (in vitro and in vivo studies)}

Sonic Hedgehog (Shh) pathway Shh pathway is one of the crucial pathways that has a role in the embryo development in various organisms; moreover, it is vital for the organogenesis process of nearly all organs and also helps in regeneration and maintaining homeostasis [95]. Shh signaling is abnormally activated in different human cancers mainly due to genetic alterations that lead to invasion, survival, proliferation, and self-renewability of the cancer stem cells allowing the rapid progress of cancer [96]. Also interestingly in diverse cancers, this signaling is activated at different stages of cancer progression and in PDAC, and it is activated in the early stages itself [97]. This Shh signaling that is highly activated in different cancers might be due to overexpression of the components involved in the pathway that occurs because of certain mutations or due to crossactivation due to other pathways [98]. As the Shh pathway showed immense involvement in the increase and survival of cancers, it was significant to target various components involved in this pathway in order to inhibit it and reduce tumor development [99].

In case of PDAC, Shh pathway is seen to be involved in the desmoplasia process that causes a dense stroma around the solid tumors making them resistant to therapeutics [100]. A key feature of PDAC is mutated KRAS oncogene which results in the expression of the Shh ligand in the very early stage of cancer [101]. Further, this Shh pathway after initiation of PDAC helps in the maintenance of the tumor and its progression and also causes resistance to all forms of therapeutics [102]. Thus, inhibition of Shh pathway by various drugs and therapeutics is widely studied in order to deal with the growing threat against PDAC; in this context, some phytochemicals are also reported to inhibit Shh pathway.

Crocetinic acid a carotenoid showed anti-PDAC activity by targeting the proteins of Shh pathway and inducing apoptosis along with inhibition of phosphorylation of Akt and sphere formation; epidermal growth factor receptor (EGFR) was also inhibited and the marker of cancer stem cells (CSCs), i.e., doublecortin calcium/calmodulin-dependent kinase 1 (DCLK-1) was downregulated showing that crocetinic acid also targeted CSCs [103]. A steroid, withaferin A inhibited Hedgehog/GLI1mediated transcriptional activity and showed inhibition of GLI1-DNA complex formation [104]. A biphenolic lignan honokiol decreased the sonic hedgehog pathway along with the decrease of CXCR4 which are responsible for crosstalk between solid tumor and stroma, and it showed suppression in migration and invasion along with the reduction in plating efficiency and anchorageindependent growth of the cancer cells [105].

Epithelial-mesenchymal transition (EMT) EMT is a process by which the epithelial cells undergo phenotypic changes like loss of cellular adhesion and apical-basal polarity which results in acquiring of mesenchymal characteristics that provide the stationary epithelial cells with migratory properties [106]. During the developmental processes, EMT is necessary for processes like organ development and gastrulation, while in adult organisms, it is important to tissue conservation, restoration of homeostasis, and reconstruction which also involves the reverse process of mesenchymal to epithelial transition 


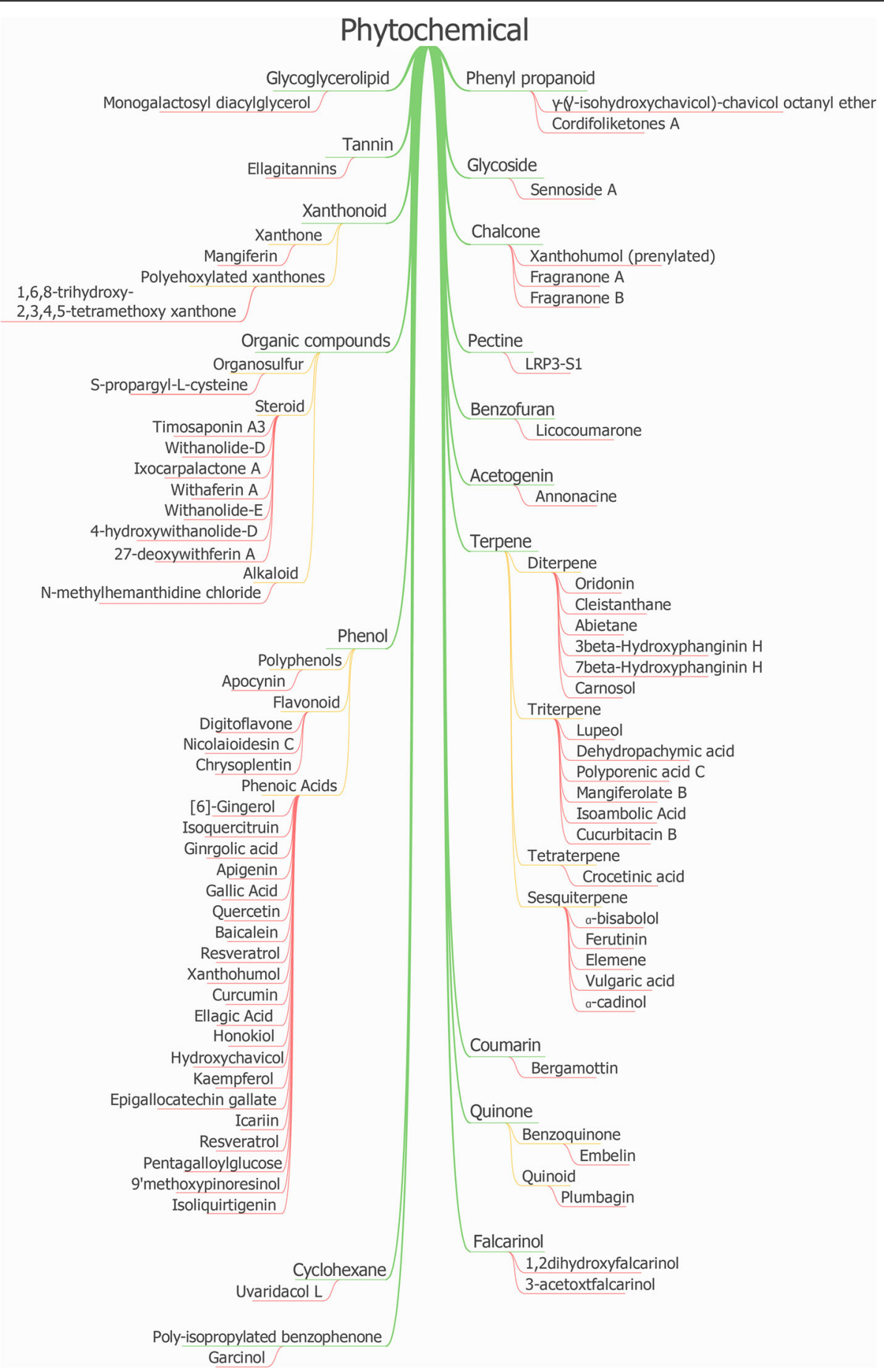

Fig. 2 Figure shows the different classification of phytochemicals that are being tested on PDAC

[107]. Also during gastrulation, EMT is responsible to give rise to mesoderm and primary mesenchyme from the primitive streak and the neural crest cells [108]. Moreover, this process is seen to occur in case of inflammation, wound healing, fibrosis, and cancer progression [109]. The involvement of EMT in cancer progression is extensively studied in the last two decades where reports have shown activation of EMT in tumor progression causing the invasive nature to be highly activated and caused local invasion, intravasation into the blood stream, and translocation through circulation, extravasation to the parenchyma of distant tissues, and survival [110]. The early steps of metastasis are initiated by EMT due to loss of or reduction in E-cadherin that facilitates 


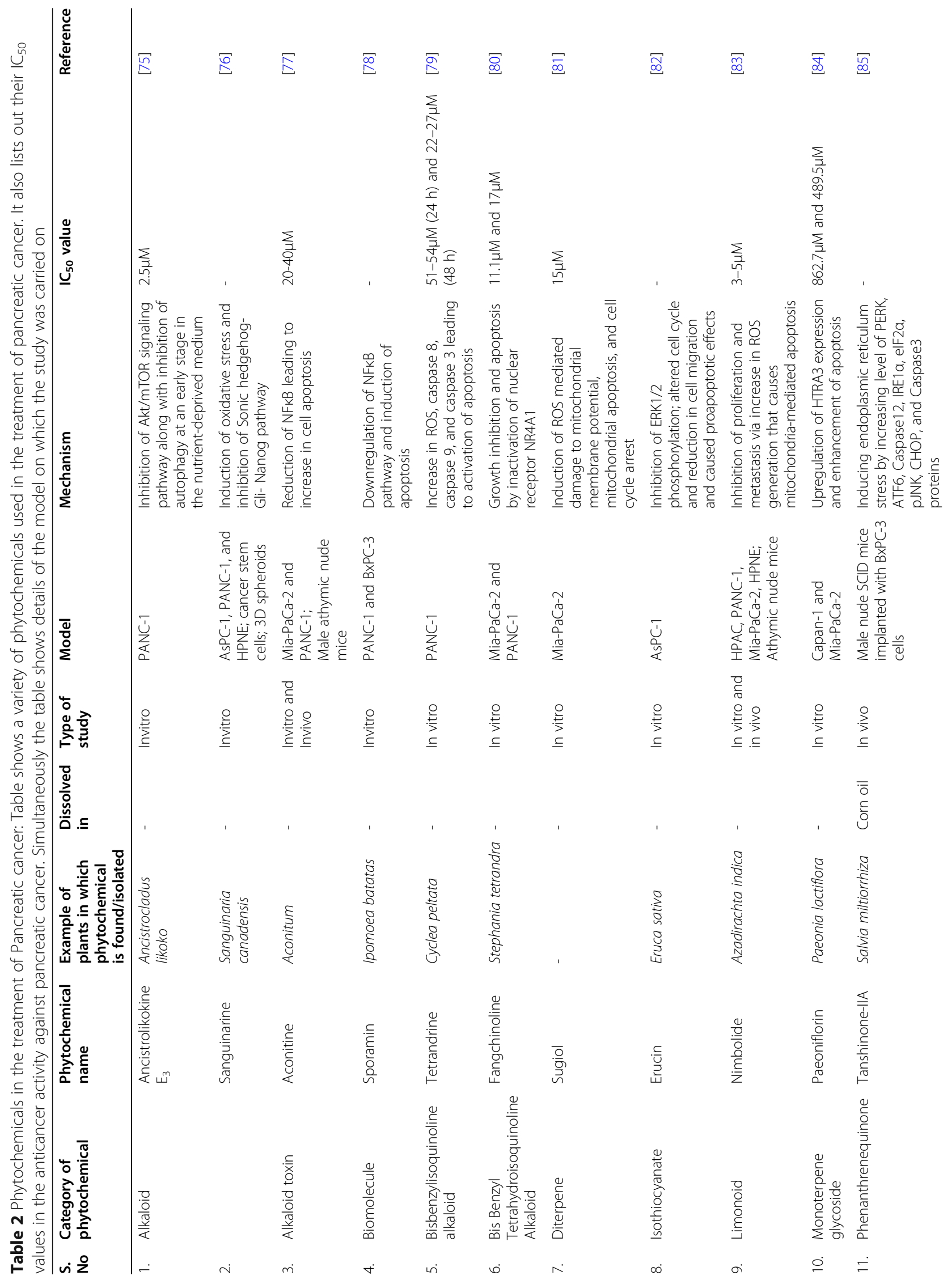




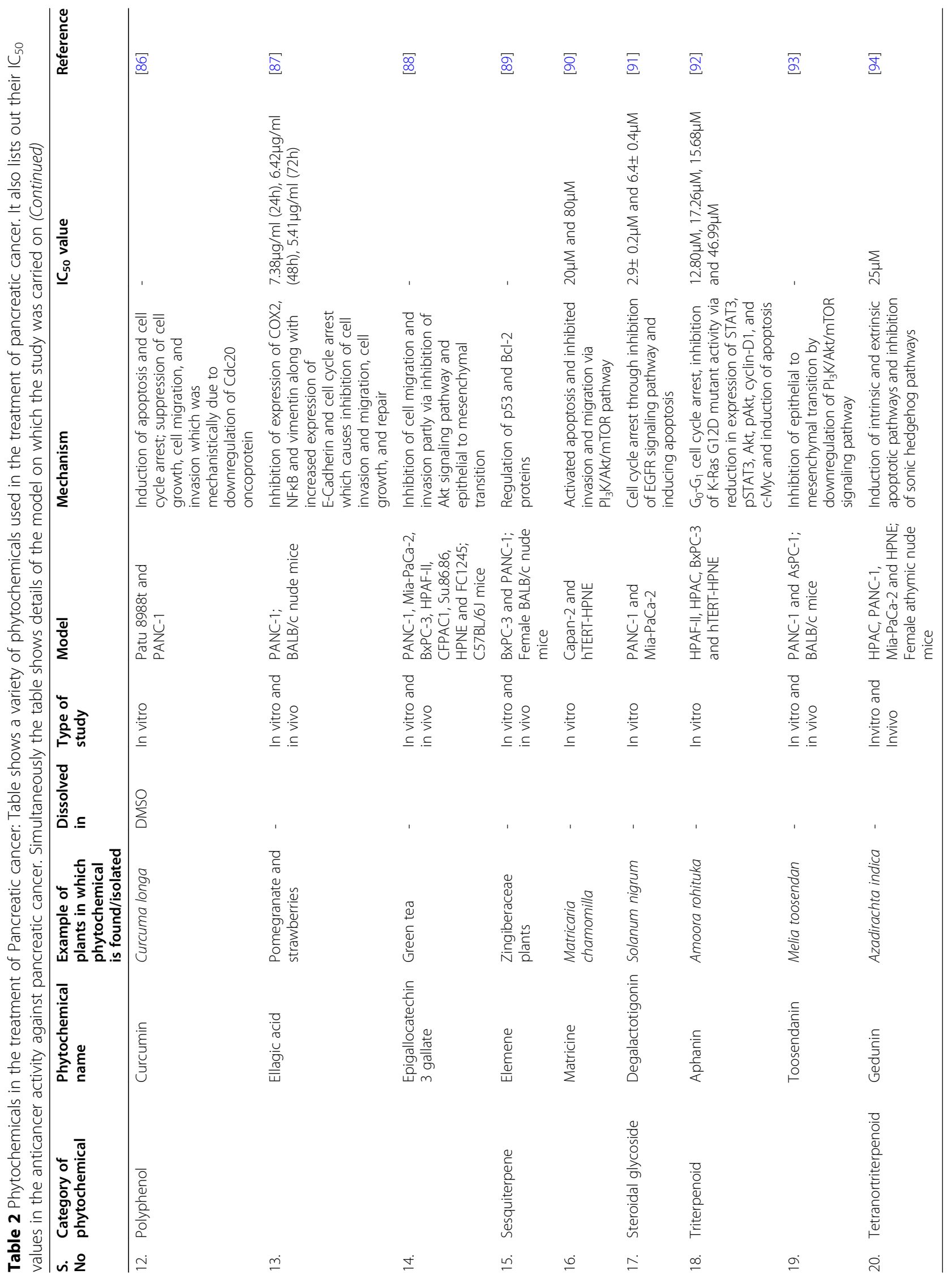


the mobility of tumor cells to distant organs [111]. EMT is also involved in drug resistance which includes mechanisms that are similar to drug resistance by cancer stem cells [112].

EMT in PDAC is found to be playing key roles relating to protein concentrating and drug transporting that provides PDAC the characteristics of being highly chemoresistant [113]. The presence of EMT along with PDAC cells that have stem cell-like properties helps the PDAC escape the present therapeutics given [114]. Even EMT is capable of helping in PDAC survival without compulsorily activating the oncogenes which makes it even more dangerous [115]. Thus, inhibiting EMT could help in dealing with PDAC and also help in reducing its chemoresistance. Certain phytochemicals showed to be inhibiting EMT and thus could be checked for being possible leads that could deal with the EMT in PDAC.

A steroid, withanolide D caused increased expression of E-cadherin causing an inversion of EMT and deactivated Akt, caused apoptosis and cell cycle arrest at $G_{2} /$ $M$ phase [116]. Proanthocyanidins from grape seed when used for treatment caused the increase of E-cadherin while fibronectin, $\mathrm{N}$ cadherin, and vimentin were decreased which showed a reversal of EMT, and also it was seen that $\mathrm{NFKB}_{\mathrm{K}}$ was inactivated along with decreased phosphorylation of ERK1/2 and cell migration was inhibited [117]. A phenol hydroxychavicol inhibited EMT and proliferation and caused DNA damage leading to mitotic catastrophe and apoptosis that is JNK and caspase-dependent, and it inhibits migration and invasion due to inhibited EMT [118]. Resveratrol (a polyphenol) and quercetin (a flavonoid) were used for treatment as monotherapy; quercetin caused a decrease in ACTA2 , IL-1 $\beta$, and N-cadherin and increase of TNF $\alpha$ and vimentin whereas resveratrol showed a decrease of $\mathrm{N}$ cadherin and TNFo; these results showed that quercetin was more effective in preventing EMT as compared to resveratrol [119].

Cell cycle arrest Cell cycle is a process responsible for the division, growth, and proliferation of the cells, development in an organism, and DNA damage repair; the cell cycle is divided into different stages like $G_{1}, S, G_{2}$, and $M$ phase [120]. During the developmental processes, the cell cycle goes on at a higher rate as compared to adult organisms, the cell cycle initiation and progression are controlled by a number of genes including cyclindependent kinases which are crucial for stopping the cell cycle when not needed and also maintaining the cell cycle arrest in the differentiated cells [121]. If this control on the cell cycle is lost due to any conditions, it causes issues in tissue homeostasis and leads to diseases like cancer [122].
Different mutations in PDAC like KRAS2, p16/ CDKN2A, TP53, and SMAD4/DPC4 are responsible for facilitating the deregulation of the cell cycle leading to uncontrolled cell division [123]. Also the cyclindependent kinases that could stop unwanted cell division are deregulated in PDAC [124]. Thus, the inhibition of the cell cycle process at different stages has served as a target for reducing tumors and certain phytochemicals are also reported to show an effect on the cell cycle.

A triterpene lupeol showed to inhibit the cell cycle at $G_{0} / G_{1}$ phase via the increase in p21 and p27 and decrease in cyclin D1; also it induced apoptosis and reduced phosphorylation of ERK and Akt which could be reversed by addition of $\mathrm{PI}_{3} \mathrm{~K} / \mathrm{Akt}$ activator [125]. A sesquiterpene, elemene, showed cell cycle arrest at $\mathrm{S}$ phase and caused the increase in p53 and decrease in $\mathrm{Bcl} 2$ [89]. Steroidal saponins, timosaponin A3, induced cell cycle arrest at sub- $G_{1}$ and $G_{2} / M$ phase and inhibition of genes like antiapoptotic $(\mathrm{Bcl} 2, \mathrm{Bcl} \mathrm{XL})$; proliferative (cyclin D1); metastatic (MMP-9) and angiogenesis (VEGF-1); and proteins like STAT3 and ERK1/2 [126]. A triterpene, cucurbitacin $B$, that showed cytotoxicity to PDAC via various ways also showed inhibition of cell cycle arrest at $G_{2} / M$ phase along with induction of apoptosis activation of JAK, STAT3, and STAT5; also it showed increase in $\mathrm{p} 21^{\text {waf1 }}$ even when the cells had a non-functional p53 and it even showed an activation in the caspase cascade [127].

A phenolic compound-rich extract of Eucalyptus microcorys caused cell cycle arrest at $\mathrm{G}_{2} / \mathrm{M}$ phase along with induction of mitochondrial apoptosis and activation of caspase cascade [128]. A triterpene, cucurbitacin B showed cell cycle arrest at $G_{2} / M$ phase along with induction of apoptosis via cas3 activation and overexpression of p53 and p21 and downregulation of $\mathrm{Bcl} 2$ and survivin, inhibition of STAT3 phosphorylation, and cell growth was also seen [129].

NFкB signaling NFкB is a regulator mechanism of inflammatory responses, and it is activated by proinflammatory cytokines like the tumor necrosis factor $\alpha$ and interleukin 1 and results in activation of expression of other genes including those of chemokines, cytokines, and adhesion molecules [130]. Along with maintaining the inflammatory responses, this mechanism is involved in adaptive and innate immunity, cellular proliferation, survival, and differentiation in many organisms [131]. The NFKB signaling is activated by two different methods that are classical and alternative pathways which are also known as the canonical and noncanonical pathways [132]. In diseases like cancer, both of these pathways are in the activated form which often results in a bad tumor prognosis as the activated $\mathrm{NFKB}_{\mathrm{K}}$ signaling supports the tumor microenvironment, apart 
from these two pathways, mutation of the upstream molecules also results in activation of NFKB [133].

In PDAC, both classical and alternate forms of NFKB signaling are activated and $\mathrm{NF}_{\kappa} \mathrm{B}$ involving pathways are critical in PDAC survival and progression, and not surprisingly, activation of $\mathrm{NF \kappa} B$ is also contributed by the KRAS mutation that is very prominent in the PDAC tumors [134]. The hypoxia environment of PDAC makes angiogenesis, drug resistance, and metastasis very favorable to occur, and $\mathrm{NFKB}$ is responsible for maintaining factors required for the same like EMT, HIF-1 $\alpha$, and VEGF; as reduction of all these is required to control the progression of PDAC, $\mathrm{NFK} B$ becomes an appealing target in PDAC tumors [135]. In this context, some phytochemicals also have the capability to inhibit NFKB signaling.

Phytochemicals like [6]-gingerol that is a phenol suppress $\mathrm{NFK}_{\mathrm{K}} \mathrm{s}$ signaling that is mediated via extracellular signal-regulated kinase (ERK) pathway and leads to suppression of invasion and regulates the tight junctions of the tumor cells [136]. A quinoid plumbagin inhibits the phosphorylation and DNA binding activities of $\mathrm{NFKB}$ along with its downstream target genes; simultaneously, it shows inhibition of DNA binding of STAT3 and its physical interaction with EGFR and induces apoptosis [137]. A flavonoid apigenin inhibited the upstream glycogen synthase kinase $3 \beta / \mathrm{NF}_{\kappa} B$ signaling pathway along with inhibition of the cell cycle at $G_{2} / M$ phase and induced mitochondrial apoptosis [138]. Activation of $N F \kappa B$ via inhibition of TNFa along with inhibition of I $\mathrm{K} B \alpha$ kinase activation and phosphorylation leads to its degradation and prevention of nuclear translocation of NFkB. Interestingly, this study also showed the inhibition of NFKB leading to activation of JNK [139].

A prenylflavonoid and isothiocyanate xanthahumol and phenethyl isothiocyanate, respectively, caused reduced binding of NFkB p65 subunit to DNA along with reduction in expression of p65 and activated the expression of Nrf2 leading to an increase in expression of GSTP, NQO1, and SOD [140].

$\mathrm{PI}_{3} \mathrm{~K} /$ Akt/mTOR pathway $\mathrm{PI}_{3} \mathrm{~K} / \mathrm{Akt} / \mathrm{mTOR}$ pathway is involved in maintaining different types of cellular metabolic mechanisms that are required for cellular proliferation and glucose metabolism [141]. Along with cellular metabolism, $\mathrm{PI}_{3} \mathrm{~K} / \mathrm{Akt} / \mathrm{mTOR}$ pathway has roles in signal transduction, apoptosis, environmental adaptation, and angiogenesis [142]. Also interestingly, $\mathrm{PI}_{3} \mathrm{~K} / \mathrm{Akt} / \mathrm{mTOR}$ pathway is the most commonly mutated in case of cancer and causes over growth [143]. In cancer conditions, $\mathrm{PI}_{3} \mathrm{~K} /$ Akt/mTOR pathway contributes towards the stimulation of survival, proliferation, invasion, metastasis, metabolic reprogramming and reduction of autophagy and death [144]. Additionally, $\mathrm{PI}_{3} \mathrm{~K} / \mathrm{Akt} / \mathrm{mTOR}$ pathway has been reported in maintaining the cancer stem cells that are necessary for the survival and several other properties like colony formation of the cancer cells [145]. And being a complex and interrelated signaling process, the inhibitors of $\mathrm{PI}_{3} \mathrm{~K} / \mathrm{Akt} / \mathrm{mTOR}$ pathway act differently on it and regulate the process of reduction of tumor survival [146].

In PDAC, again KRAS mutation is being evidenced to be related to triggering the $\mathrm{PI}_{3} \mathrm{~K} / \mathrm{Akt} / \mathrm{mTOR}$ pathway, and inhibition of this pathway can prove to be a good therapeutic approach, but due to its complexity and interrelated signaling, it is difficult to be targeted [147]. Also this mechanism is seen to be playing a pivotal role in PDAC dysplasia and hence needs to be targeted [148]. Some phytochemicals have shown that they could act as potential leads to target the $\mathrm{PI}_{3} \mathrm{~K} / \mathrm{Akt} / \mathrm{mTOR}$ pathway at various points and thus help in dealing with PDAC.

Embelin a benzoquinone showed inhibition of the Akt pathway along with inhibition of cell proliferation, angiogenesis, EMT, and metastasis; it also induced apoptosis and cell cycle arrest [149]. An amaryllidaceae alkaloid, $N$-methylhemeanthidine chloride caused inhibition of Akt pathway along with induction of apoptosis in order to cause PDAC cell death [150]. A sesquiterpene alcohol, $\alpha$-bisabolol showed suppression of Akt activation and increase in early growth response 1 and apoptosis [151]. A coumarin, bergamottin, inhibited survival proteins of Akt/mTOR pathway along with causing cell shrinkage, membrane bleeding, and disintegration of cell organelles and also inhibited cell migration and colony formation [152]. A triterpene, cucurbitacin B, showed inhibition of $\mathrm{PI}_{3} \mathrm{~K} / \mathrm{Akt} / \mathrm{mTOR}$ pathway and STAT3 pathway due to inhibition of expression and activity of EGFR, and it also showed cell cycle arrest at $G_{2} / M$ phase but it showed activation of ERK by AMPK activation [153].

Proanthocyanidins from grape showed a decrease in $\mathrm{PI}_{3} \mathrm{~K}$ and phosphorylation of Akt at Ser473, it also showed cell cycle arrest and induction of apoptosis along with reduced cell viability and cell cycle arrest, and levels of Bcl2 and Bcl XL were decreased with an increase in Bax and activated Cas3 [154]. A pectin LRP3-S1 showed downregulation of phosphorylated FAK, Akt, GSK-3 $\beta$, and $\mathrm{p} 38$ protein expression and attenuated invasion and inhibited growth [155]. Kaempferol a flavonoid inhibited EGFR-related ERK1/2 and Akt pathway and caused inhibition of migration and induction of apoptosis [156]. A steroid, withaferin $\mathrm{A}$, showed inactivation of $\mathrm{PI}_{3} \mathrm{~K} / \mathrm{Akt}$ pathway and mitochondrial dysfunction along with enhanced growth suppression and induction of apoptosis and accumulation of ROS [157].

c-Jun $\mathrm{NH}_{2}$ terminal kinase (JNK) pathway The JNK pathway is one of the sub-groups belonging to the mitogen-activated protein kinase family of signaling proteins and is activated under stress conditions by cytokines [158]. JNK in almost all the eukaryotic cells is 
responsible for showing responses against various biotic and abiotic stress, and also it has roles in embryo development, neuronal functions, dynamics of cytoskeleton proteins, and cell survival or death; even though this mechanism has so many functions, it remains one of the under studied cellular pathway [159]. Because of being less studied, the role of JNK in cancer remains controversial as it has a variety of upstream and downstream signaling that function in a varied manner from one another, and thus, JNK which was initially proved to be involved in cell death processes is now debated for being responsible for cancer cell survival [160]. JNK has been reported to be playing a significant role in apoptosis and also increasing the expression of proapoptotic genes [161, 162].

Even in PDAC JNK pathway is not studied robustly and needs more evidence for clear understanding and better dealing as a drug target. However, it is seen that the phosphorylation of JNK supports apoptotic cell death, and in this support, certain phytochemicals have proofed their roles.

A flavonoid isoquercetin promoted the phosphorylation process of JNK and inhibited phosphorylation of ERK along with inhibition of $\delta$ opioid receptors and no effect on $\mu$ and $\kappa$ opioid receptors; it also induced apoptosis and cell cycle arrest along with activation of caspase cascade leading to loss of mitochondrial membrane potential [163]. A phytochemical S-propargyl-Lcysteine of a different group, i.e., an organosulfur was also reported to cause phosphorylation of JNK and reduced polyubiquitination-mediated degradation of JNK causing tumor cell death; along with these processes, it also showed increased apoptosis, cell cycle arrest in the $\mathrm{G}_{2} / \mathrm{M}$ phase, and reduction of cell proliferation, viability, and colony formation [164]. Eriocalyx a diterpene showed induction of phosphorylation of JNK with the reduction of PDK1 and Akt phosphorylation and increased caspase cascade causing apoptosis and antiproliferative effect [165].

Mitochondria-dependent apoptosis Apoptosis is defined as a programmed cell death process that is controlled by a number of proteins and specific cellular signaling [166]. It occurs in processes like aging, development, and maintenance of homeostasis and also it occurs in case of immune responses, defense mechanisms, and cells are in a condition of cell damage by disease and other foreign agents [167]. Apoptosis might be mitochondrial-dependent or independent, and the majority of the times, it is mitochondria-dependent and involves the breakdown of mitochondrial membrane potential [168]. Deregulation of the apoptotic cell death is the signature hallmark of cancer, and the difference in the normal apoptotic signaling helps in tumor progression, development, and also drug resistance; hence, this mechanism is targeted for inducing cancer cell death [169]. Therefore, it is not surprising that targeting this mitochondrial-dependent apoptosis is now gaining importance for the treatment of cancer [170].

In PDAC, tumor resistance to various chemotherapies and radiotherapies is attributed due to the dysfunction of the apoptotic cell death process [171]. Mitochondriadependent apoptosis or intrinsic apoptotic pathway is greatly defected in PDAC and plays key roles in several processes of tumor progression and disrupted cellular homeostasis [172]. As this intrinsic apoptotic method was identified as a central pathway related to many other pathways in PDAC tumor, it was exploited for being the drug target [173]. And many phytochemicals have also shown to trigger apoptotic cancer cell death via intrinsic pathway and been helpful in dealing with the threats of the tumor.

Examples include grape seed proanthocyanidins that induce apoptosis along with inhibition of cell migration and downregulation of MiR-27a and upregulation of FOXO1 [174]. Another study done using proanthocyanidins also showed induction of apoptosis along with a decrease in proliferation and migration rates and an increase in expression of Let 7a [175]. A prenylated chalcone, xanthohumol, was tested and found to show induction of apoptosis by inhibition of phosphorylation of STAT3 and expression of cyclin D1, survivin, and Bcl-XL that also lead to cell cycle arrest [176]. A phenol, gallic acid, caused mitochondrial-dependent apoptosis by activating the caspase 3 , caspase 9 , and reactive oxygen species (ROS) along with an increase in Bax expression and reduction of mitochondrial membrane potential [177]. A flavonoid, quercetin, showed apoptosis when given in monotherapy, and when given in combination with gemcitabine, it did not show any synergistic effect [178]. Another flavonoid, baicalein, induced apoptosis and increased proapoptotic genes and reduced antiapoptotic proteins [179]. Two falcarinols, 1,2-dihydrofalcarinol and 3-acetoxyfalcarinol, showed modulation in the genes that are related to pro- and anti-apoptosis process and also affected cell cycle and stress-related death receptors [180].

A combination of a polyphenol ellagic acid and a benzoquinone embelin caused apoptosis also in monotherapy, and they were seen to cause apoptosis, but in case of monotherapy, treatment for ellagic acid decrease in $\mathrm{NF}_{\kappa} \mathrm{B}$ was also seen, and in case of embelin, decreased phosphorylation of STAT3 along with downregulation of downstream protein survivin was seen [181]. Phenol, gallic acid, depolarized mitochondrial membrane potential and induced apoptosis and reduced $\mathrm{Bcl} 2$ expression and ROS generation and also inhibited cell proliferation [182]. A poly isoprenylated benzophenone, garcinol, induced apoptosis along with inhibiting cell proliferation 
and modulated PARP, VEGF, MMPs, ILs, caspases, and NFкB [183]. Procyanidins from grape seed showed induction of mitochondrial apoptosis and cell cycle arrest at $G_{1}$ phase along with inhibition of cell proliferation and adhesion and invasion potential due to suppression of matrix metalloproteases 9 or 2 [184]. Two polymethoxylated xanthones, i.e., 1,6,8-trihydroxy-2,3,4,5-tetramethoxyxanthone and 1,6-dihydroxy-2,3,4,5,8-pentamethoxyxanthone, showed to cause apoptosis-mediated cell death [185].

2'-4'Dihydroxy-6' methoxy-3',5'-dimethylchalcone, a chalcone, has shown to induce apoptosis via activation of caspase 3 and caspase 9, and it degraded cas3 substrate protein including PARP and augmented the Bak protein levels and attenuated the level of $\mathrm{Bcl} 2$ protein [186]. A phenylpropanoid, cordifoliketone A induces apoptosis, suppresses migration and invasion, and causes inhibition of proliferation [187].

Autophagy Autophagy is a process by which carries on functions like housekeeping for the cells, it helps in the removal of unwanted substances from the cell-like damaged organelles and aggregated or misfolded proteins, it helps the cell by acting as a defense mechanism during pathogen attack and nutritional starvation [188]. The key component in the mechanism is the formation of autophagosome which is a double membrane organelle; this autophagosome further combines with a lysosome to form autophagolysosome or autolysosome and then degrades the material carried in it [189]. In case of diseases like cancer, autophagy plays a non-defined role, and in that, it is seen to show tumor-suppressive nature in the early stages of tumor development, but in the late stage of development, it serves the purpose of protecting the tumor cells from the immune system [190]. Basically, as autophagy is involved in cleaning, degrading, and resupplying of materials to the cells when they are in nutrient-deprived or starvation condition, when the cancer cells are progressing towards the late stages, the autophagy process provides them with the required nutrients for tumor growth [191]. As autophagy has both cancer-promoting and suppressing roles, hence both the inhibition and activation of autophagy are considered as targets for cancer therapies [192].

Autophagy in PDAC has a conflicting role that still remains a topic of debate, and many in vivo and in vitro studies have shown that autophagy has roles in PDAC survival and growth but those same studies also pointed towards the fact that autophagy has both pro- and antiroles in case of PDAC tumor progression, and thus, the role of autophagy in case of PDAC still remains unclear [193]. Supporting the same context, certain phytochemicals have shown to inhibit and rest has shown to induce autophagy to cause PDAC cell death.
A sesquiterpene, $\alpha$-cadinol, showed cytotoxicity in PDAC tumor cells in nutrient-deprived media by the hyperactivation of autophagy along with inhibition of the activation process of Akt/mTOR pathway [194]. Callistrilone $\mathrm{L}$ a meroterpenoid showed activation of autophagy along with inhibition of Akt/mTOR pathway and also inhibited cell migration and colony formation; all these effects were seen in nutrient-deprived media [195]. A xanthone mangiferin showed to induce autophagy and caused LC3 II and Beclin 1 expression to increase; also it showed cell cycle arrest and apoptosis along with ROS generation and suppressed migration and invasion [196]. Withaferin A, a steroid, showed that it can cause an increase in autophagososme formation but blocks the degradation of those autophagic cargoes via inhibition of SNARE-mediated fusion of autophagosome and lysosome, and also it causes proteasome inhibition and accumulation of ubiquitinated protein resulting in endoplasmic reticulum stress and apoptosis; due to endoplasmic reticulum stress, autophagy was induced in the early stage [197].

Other mechanisms Certain phytochemicals show varied mechanisms that are rare. For example, ginkgolic acid caused inhibition of de novo lipogenesis through inducing activation of AMP-activated protein kinase (AMPK) signaling and downregulation of key enzymes like acetyl CoA carboxylase $[\mathrm{ACC}]$ and fatty acid synthase [FASN]. Along with this inhibition, it shows induction of apoptosis and impaired migration, invasion, and colony formation [198]. A diterpene oridonin showed differential expression of 105 different miRNAs that caused PDAC cell death [199]. Abeitane diterpenes showed inhibition of topoisomerase I along with the effect on cell cycle progression and caused cell cycle arrest at $G_{1} / G_{0}$ and $S$ phase and generated ROS [200]. An acetogenin, annonacin, inhibited sodium/potassium ATPase pumps and Sarcoplasmic reticulum ATPase pumps [201]. A terpenoid, ferutinin, caused cell shrinkage and inhibited colony formation in nutrient-deprived media [202]. A flavonoid, apigenin, that showed inhibition by NFKB was reported to induce PDAC cell death by other mechanism, and also it was seen that apigenin was able to inhibit the cell proliferation, FAK, and ERK that was induced by a carcinogen 4-(methylnitrosamino)-1-(3-pyridyl)-1-butanone (NNK) and also prevented the gap closure that was caused by NNK [203].

Two triterpens, dehydropachymic acid and polyporenic acid, reduced the expression of $\mathrm{CDC} 20$ and suppressed migration [204]. A chalcone, fragranone A, suppresses cell migration in nutrient-deprived media [205]. Two polyphenols, resveratrol and apocynin, showed inactivation of Akt/GSK3 $\beta$ and ERK1/2 signaling due to decreased phosphorylation of GSK3 $\beta$ and ERK1/2 and inhibition of cell cycle at $G_{1}$ phase [206]. A triterpene, cucurbitacin $B$, that 
induces PDAC cell death by well-known mechanisms also showed certain rare mechanism in which it showed to inhibit expression of actin-filament-associated protein 1 antisense RNA 1 (AFAP-1 AS1) which caused cell cycle arrest; also it was seen that the expression of miR-146b-5p was increased [207]. Cucurbitacin B was also checked in vivo in combination with gemcitabine, and it was seen to cause tumor growth inhibition, activation of the caspase cascade, and inhibition of Bcl-XL, Bcl2, and c-myc [208]. Also when PDAC cells were knockout for $\operatorname{NAD}(\mathrm{P}) \mathrm{H}$ : quinone oxidoreductase 1 (NQO1), cucurbitacin $\mathrm{B}$ was capable of re-establishing NQO1 expression, stabilizing p53, and increasing their interaction which resulted in a longer half-life of p53 [209]. A glycoside, sennoside A, caused an increase in cofilin phosphorylation that caused impaired actin dynamics which may or may not be linked with EGFR stimulation and reduced the motility and invasiveness which in all showed sennoside A as a slingshot inhibitor [210].

A steroid ixocarpalactone A showed inhibition of 3phosphoglycerate dehydrogenase (PHGDH) by directly binding to it and inhibited proliferation, and also it showed proapoptotic activities [211]. A benzofuran, licocoumarone, inhibited dual-specificity tyrosine phosphorylationregulated kinase 1A (DYRK1A) and reduced cMET protein and suppressed proliferation by induction of apoptosis [212]. Epigallocatechin gallate a polyphenol caused reduced lactate production, anaerobic glycolysis, glucose consumption, and glycolytic rate and causes a change in intracellular glucose carbon-re-distribution among the major glucose utilizing macromolecule biosynthesis that leads to disruption of the balance flux throughout the cellular metabolic network [213]. A glycoglycerolipid, monogalactosyl diacylglycerol, reduces colony formation and when combined with radiation and it causes an increase in apoptosis associated with increased mitochondrial and DNA damage [214]. Icariin, a flavonoid, inhibits polarization of RAW 264.7 cells into M2 macrophages by inhibiting the expression of ARG1 and MRC1 and downregulating IL4-STAT6 pathway along with inhibition of migration and proliferation and induction of apoptosis [215].

A steroid withaferin A along with a diterpene carnosol shows that they can target the pancreatic CSCs, and they show reduced HGF-mediated proliferation in $\mathrm{cMET}^{+}$ cells along with increased apoptosis and altered cell cycle; also they induce a reduction in migration with suppression of cMET phosphorylation and diminished sphere and colony formation that was proved by a reduction in pluripotent genes Oct4 and nanog [216]. The same steroid was seen to show a different mechanism to inhibit the growth of cancer cells. It caused inhibition of cell proliferation and induction of cas 3 activity and directly binded to Hsp90 and caused its aggregation, thus inhibiting its activity and causing degradation of its client proteins like Akt and Cdk4 via a proteasomedependent pathway. It also disrupted the Hsp90-Cdc37 complex, and the structure-activity relation studies showed that C-5(6)-epoxy functional group facilitates the binding of withaferin A to Hsp90 and the hydroxyl group at the c-4 in ring $\mathrm{A}$ enhances the inhibition of Hsp90 and disruption of Hsp90-cdc37 [217]. Also in another study, it showed to inhibit Hsp90 chaperone activity and induced the degradation of its client proteins like Akt, Cdk4, and glucocorticoid receptor; all these were reversed by proteasomal inhibitor MG132, and the study showed that withaferin binds the c terminal of Hsp90 to cause disruption of Hsp90-Cdc37 [218].

Epigallocatechin-3-gallate, a polyphenol, induced ROS and affected glycolysis by suppressing extracellular acidification rates through reduction of activity and levels of glycolytic enzymes like pyruvate kinase and phosphofructokinase [219]. A flavonoid quercetin that shows varied mechanisms to kill PDAC tumor also showed upregulation of miR let $7 \mathrm{C}$ which leads to inhibition of colony formation, wound healing, and progression markers and also caused notch inhibition [220]. Another polyphenol $\beta$-pentagalloyl-glucose inhibited insulin receptor/insulin-like growth factor-1 receptor activity that decreased the glycolytic enzymes, and it was shown that this compound combats PDAC and also cures cancer cachexia [221].

No mechanism defined There are certain phytochemicals that have shown inhibitory effects on PDAC tumor but their mechanism of action is not explored yet and requires further investigation. Some of them are cleistanthane diterpenes from Caesalpinia sappan in nutrient-deprived media [222]; a methoxyflavonol, chrysoplenetin from Vitex negundo [223]. A sesquiterpene, vulgaric acid, showed moderate toxicity and a flavonoid apigenin showed strong toxicity [224]. A triterpenoid, mangiferolate $B$, caused cell death in nutrient-deprived condition [225]; Tannin, ellagitannins from Cistaceae aqueous extract [226]. A flavonoid and a secondary metabolite nicolaioidesin $\mathrm{C}$ and isopanduratin $\mathrm{A} 1$, respectively, from rhizomes of Boesenbergia pandurata caused PDAC cell death in nutrient-deprived media [227].

Diterpenoids from Caesalpinia decapetala were seen to cause cytotoxicity [228]. Uvaridacol L a cyclohexene from the leaves of Uvaria dac showed cancer cell death in nutrient-deprived media [229]. A lignan 9' methoxypinoresinol shows inhibition of colony formation in the PDAC tumor [230]. A phenylpropanoid from leaves of Piper betle [231].

\section{Conclusions}

In conclusion, we would like to highlight the fact that plants and their phytoconstituents play a key role in 


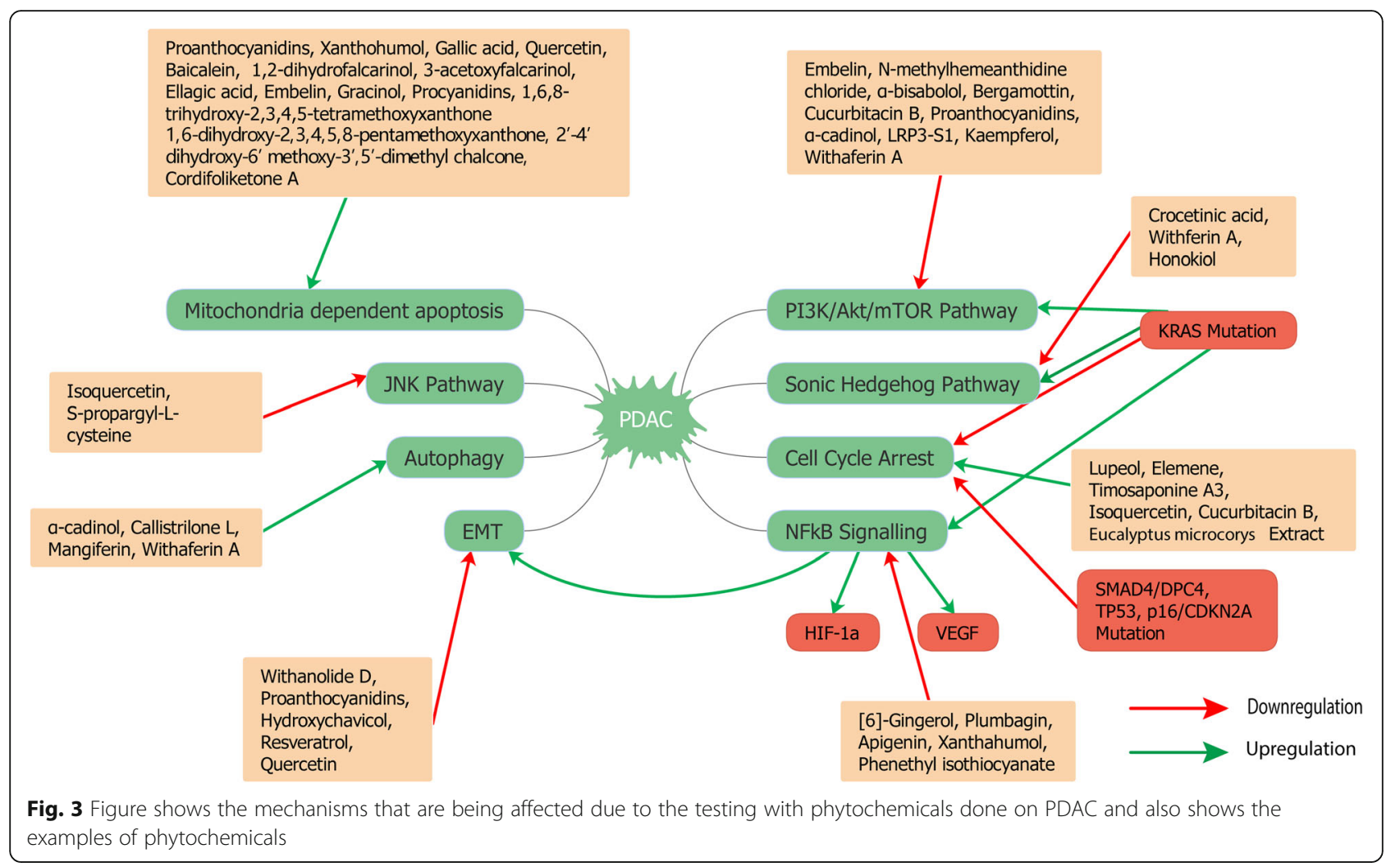

combating PDAC tumors. They could be used as monotherapy or combination therapy along with the existing drugs. The phytoconstituents have shown to be very effective in reducing the resistance that is occurred in PDAC to classical chemotherapeutics. They have paved ways to deal with the issues hindering the treatment of cancer and increase of survival of the patient. Interestingly, plants and phytoconstituents have shown to acts robustly on the tumor and also have the plus points of not showing toxicity Fig. 3.

In the above discussions, it is very clear that not all plants belonging to the same family have the same effect and not all phytochemicals going to one group have the same mechanism of action. Even it should be noticed that the same plant may have different activities and one particular phytoconstituent has several mechanisms. This brings into light that still many plants that are not explored have the possibility to be showing efficient results and the phytochemicals that are not checked could show more efficiency. This brings a hope that a combination of the plants and phytoconstituents with the classical or synthetic drugs could induce and reduce multiple mechanisms simultaneously that will all lead to the death of PDAC tumor. There are billions of plant species and even more phytoconstituents, and each of which could be a key to open solutions to the questions still persistent in case of treating PDAC.

\section{Abbreviations}

EMT: Epithelial-mesenchymal transition; HPLC: High-performance liquid chromatography; JNK: c-Jun $\mathrm{NH}_{2}$ terminal kinase; MTT: 3-(4, 5-

Dimethylthiazol-2-yl)-2, 5-diphenyl tetrazolium bromide; PC: Pancreatic cancer; PDAC: Pancreatic ductal adenocarcinoma; Shh: Sonic Hedgehog; TEM: Transmission electron microscopy

\section{Acknowledgements}

The authors are thankful to the Central University of Rajasthan, Bandarsindri, Ajmer, for providing facilities such as journals and Internet sources for writing the review article.

\section{Authors' contributions}

Conceptualization, investigation, data curation, writing, original draft preparation: SG. Data curation and figure preparation: AK. Writing review, editing, supervision: SG and KKT. The authors have read and approved the final manuscript.

\section{Funding}

This research did not receive any specific grant from funding agencies in the public, commercial, or not-for-profit sectors.

\section{Availability of data and materials}

All data generated or analyzed during this study are included in the published article.

\section{Declarations}

Ethics approval and consent to participate

Not applicable.

\section{Consent for publication}

Not applicable.

\section{Competing interests}

The authors declare that they have no competing interests. 


\section{Received: 2 March 2021 Accepted: 16 April 2021}

\section{Published online: 04 May 2021}

\section{References}

1. Gilles ME, Hao L, Brown K, Lim J, Bhatia SN, Slack FJ (2019) Tumor penetrating nanomedicine targeting both an oncomiR and an oncogene in pancreatic cancer. Oncotarget 10(51):5349-5358. https://doi.org/10.18632/ oncotarget. 27160

2. Bray F, Ferlay J, Soerjomataram I, Siegel RL, Torre LA, Jemal A (2018) Global cancer statistics 2018: GLOBOCAN estimates of incidence and mortality worldwide for 36 cancers in 185 countries. CA Cancer J Clin 68(6):394-424. https://doi.org/10.3322/caac.21492

3. Chandran S, Patgiri B, Bedarkar P, Mathat D (2019) Anticancer activity of Yashada Bhasma (bioactive nanoparticles of zinc): a human pancreatic cancer cell line study. Ayu 40(1):58-63. https://doi.org/1 0.4103/ayu.AYU_239_17

4. Ma ZY, Gong YF, Zhuang HK, Zhou ZX, Huang SZ, Zou YP, Huang BW, Sun ZH, Zhang CZ, Tang YQ, Hou BH (2020) Pancreatic neuroendocrine tumors: a review of serum biomarkers, staging, and management. World J Gastroenterol 26(19):2305-2322. https://doi.org/10.3748/wjg.v26.i19.2305

5. Torphy RJ, Fujiwara Y, Schulick RD (2020) Pancreatic cancer treatment: better, but a long way to go. Surg Today. https://doi.org/10.1007/s00595-02 0-02028-0

6. Poty S, Mandleywala K, O'Neill E, Knight JC, Cornelissen B, Lewis JS (2020) (89)Zr-PET imaging of DNA double-strand breaks for the early monitoring of response following $\alpha$ - and $\beta$-particle radioimmunotherapy in a mouse model of pancreatic ductal adenocarcinoma. Theranostics 10(13):5802-5814. https://doi.org/10.7150/thno.44772

7. Rawla P, Sunkara T, Gaduputi V (2019) Epidemiology of pancreatic cancer: global trends, etiology and risk factors. World J Oncol 10(1):10-27. https:// doi.org/10.14740/wjon1166

8. Du C, da Silva A, Morales-Oyarvide V, Dias Costa A, Kozak MM, Dunne RF, Rubinson DA, Perez K, Masugi Y, Hamada T, Brais LK, Yuan C, Babic A, Ducar MD, Thorner AR, Aguirre A, Kulke MH, Ng K, Clancy TE, Findeis-Hosey JJ, Chang DT, Hornick JL, Fuchs CS, Ogino S, Koong AC, Hezel AF, Wolpin BM, Nowak JA (2020) Insulin-like growth factor-1 receptor expression and disease recurrence and survival in patients with resected pancreatic ductal adenocarcinoma. Cancer Epidemiol Biomarkers Prev. https://doi.org/10.11 58/1055-9965.EPI-19-1315

9. Orth M, Metzger P, Gerum S, Mayerle J, Schneider G, Belka C, Schnurr M, Lauber K (2019) Pancreatic ductal adenocarcinoma: biological hallmarks, current status, and future perspectives of combined modality treatment approaches. Radiat Oncol 14(1):141. https://doi.org/10.1186/ s13014-019-1345-6

10. Braun LM, Lagies S, Guenzle J, Fichtner-Feigl S, Wittel UA, Kammerer B (2020) Metabolic adaptation during nab-paclitaxel resistance in pancreatic cancer cell lines. Cells 9(5). https://doi.org/10.3390/cells9051251

11. Bayala B, Zoure AA, Baron S, de Joussineau C, Simpore J, Lobaccaro JA (2020) Pharmacological modulation of steroid activity in hormonedependent breast and prostate cancers: effect of some plant extract derivatives. Int J Mol Sci 21(10). https://doi.org/10.3390/ijms21103690

12. Aboalola DM, Weli AM, Hossain MA, Touby SA (2020) Toxicological study of various crude extracts of Hyoscyamus gallagheri native to Oman. Toxicol Rep 7:680-684. https://doi.org/10.1016/j.toxrep.2020.05.004

13. Alper $M$, Güneş $H$ (2019) The anticancer and anti-inflammatory effects of centaurea solstitialis extract on human cancer cell lines. Turk J Pharm Sci 16(3):273-281. https://doi.org/10.4274/tjps.galenos.2018.27146

14. Rahi MS, Islam MS, Jerin I, Jahangir CA, Hasan MM, Hoque KMF, Reza MA (2020) Differential expression of Bax-BCl-2 and PARP-1 confirms apoptosis of EAC cells in Swiss albino mice by Morus laevigata. J Food Biochem:e13342. https://doi.org/10.1111/jfbc.13342

15. Guerrero-Rubio MA, Hernández-García S, Escribano J, Jiménez-Atiénzar M, Cabanes J, García-Carmona F, Gandía-Herrero F (2020) Betalain healthpromoting effects after ingestion in Caenorhabditis elegans are mediated by DAF-16/FOXO and SKN-1/Nrf2 transcription factors. Food Chem 330: 127228. https://doi.org/10.1016/j.foodchem.2020.127228

16. Zengin G, Mahomoodally MF, Rocchetti G, Lucini L, Sieniawska E, Świątek $Ł$, Rajtar B, Polz-Dacewicz M, Senkardes I, Aktümsek A, Picot-Allain MCN, Montesano D (2020) Chemical characterization and bioactive properties of different extracts from fibigia clypeata, an unexplored plant food. Foods 9(6). https://doi.org/10.3390/foods9060705
17. Prado LG, Arruda HS, Peixoto Araujo NM, de Oliveira Braga LE, Banzato TP, Pereira GA, Figueiredo MC, Ruiz A, Eberlin MN, de Carvalho JE, VendraminiCosta DB, Pastore GM (2020) Antioxidant, antiproliferative and healing properties of araticum (Annona crassiflora Mart.) peel and seed. Food Res Int 133:109168. https://doi.org/10.1016/j.foodres.2020.109168

18. Lee JJ, Saiful Yazan L, Kassim NK, Che Abdullah CA, Esa N, Lim PC, Tan DC (2020) Cytotoxic Activity of Christia vespertilionis root and leaf extracts and fractions against breast cancer cell lines. Molecules (Basel, Switzerland) 25(11). https://doi.org/10.3390/molecules25112610

19. Oikpefan EO, Ayinde BA, Mudassir A, Farooq AD (2019) Comparative in vitro assessment of the methanol extracts of the leaf, stem, and root barks of Cnidoscolus aconitifolius on lung and breast cancer cell lines. Turk J Pharm Sci 16(4):375-379. https://doi.org/10.4274/tjps.galenos.2018.19942

20. Nguyen NH, Ta QTH, Pham QT, Luong TNH, Phung VT, Duong TH, Vo VG (2020) Anticancer activity of novel plant extracts and compounds from adenosma bracteosum (Bonati) in human lung and liver cancer cells. Molecules (Basel, Switzerland) 25(12). https://doi.org/10.3390/molecules2 5122912

21. Prabhakaran K, Ramasamy G, Doraisamy U, Mannu J, Rajamani K, Murugesan JR (2016) Polyketide natural products, acetogenins from graviola (Annona muricata L), its biochemical, cytotoxic activity and various analyses through computational and bio-programming methods. Curr Pharm Des 22(34): 5204-5210. https://doi.org/10.2174/1381612822666160531163144

22. Khodavirdipour A, Zarean R, Safaralizadeh R (2020) Evaluation of the anticancer effect of Syzygium cumini ethanolic extract on HT-29 colorectal cell line. J Gastrointest Cancer. https://doi.org/10.1007/s12029-020-00439-3

23. Almeida AA, Lima GDA, Simão M, Moreira GA, Siqueira RP, Zanatta AC, Vilegas W, Machado-Neves M, Bressan GC, Leite JPV (2020) Screening of plants from the Brazilian Atlantic Forest led to the identification of Athenaea velutina (Solanaceae) as a novel source of antimetastatic agents. Int J Exp Pathol. https://doi.org/10.1111/iep.12351

24. Joshi PR, Paudel MR, Chand MB, Pradhan S, Pant KK, Joshi GP, Bohara M, Wagner SH, Pant B, Pant B (2020) Cytotoxic effect of selected wild orchids on two different human cancer cell lines. Heliyon 6(5):e03991. https://doi. org/10.1016/j.heliyon.2020.e03991

25. Turner A, Bond DR, Vuong QV, Chalmers A, Beckett EL, Weidenhofer J, Scarlett CJ (2020) Elaeocarpus reticulatus fruit extracts reduce viability and induce apoptosis in pancreatic cancer cells in vitro. Mol Biol Rep 47(3): 2073-2084. https://doi.org/10.1007/s1 1033-020-05307-8

26. Kim M, Mun JG, Lee HJ, Son SR, Lee MJ, Kee JY (2019) Inhibitory effect of oat bran ethanol extract on survival and gemcitabine resistance of pancreatic cancer cells. Molecules (Basel, Switzerland) 24(21). https://doi. org/10.3390/molecules24213829

27. Huang XF, Chang KF, Lee SC, Li CY, Liao HH, Hsieh MC, Tsai NM (2020) Extract of Juniperus indica Bertol synergizes with cisplatin to inhibit oral cancer cell growth via repression of cell cycle progression and activation of the caspase cascade. Molecules (Basel, Switzerland) 25(12). https://doi.org/1 0.3390/molecules 25122746

28. Nguyen VT, Sakoff JA, Scarlett CJ (2017) Physicochemical properties, antioxidant and anti-proliferative capacities of dried leaf and its extract from Xao tam phan (Paramignya trimera). Chem Biodivers 14(6). https://doi.org/1 $0.1002 / c b d v .201600498$

29. Nguyen VT, Scarlett CJ (2019) Cytotoxic activity of extracts and fractions from Paramignya trimera root and Phyllanthus amarus against pancreatic cancer cell lines. J Cancer Res Ther 15(1):245-249. https://doi.org/10.4103/ jcrt.JCRT_85_18

30. Shimizu T, Torres MP, Chakraborty S, Souchek JJ, Rachagani S, Kaur S, Macha M, Ganti AK, Hauke RJ, Batra SK (2013) Holy Basil leaf extract decreases tumorigenicity and metastasis of aggressive human pancreatic cancer cells in vitro and in vivo: potential role in therapy. Cancer Lett 336(2):270-280. https://doi.org/10.1016/j.canlet.2013.03.017

31. Hii LW, Lim SE, Leong CO, Chin SY, Tan NP, Lai KS, Mai CW (2019) The synergism of Clinacanthus nutans Lindau extracts with gemcitabine: downregulation of anti-apoptotic markers in squamous pancreatic ductal adenocarcinoma. BMC Complement Altern Med 19(1):257. https://doi.org/1 0.1186/s12906-019-2663-9

32. Rahman HS (2018) Phytochemical analysis and antioxidant and anticancer activities of mastic gum resin from Pistacia atlantica subspecies kurdica. Onco Targets Ther 11:4559-4572. https://doi.org/10.2147/OTT.S170827

33. Kang Y, Yoon SW, Park B (2018) Allergen-removed Rhus verniciflua Stokes suppresses invasion and migration of pancreatic cancer cells through 
downregulation of the JAK/STAT and Src/FAK signaling pathways. Oncol Rep 40(5):3060-3068. https://doi.org/10.3892/or.2018.6699

34. Dong R, Chen P, Chen Q (2018) Extract of the medicinal plant pao pereira inhibits pancreatic cancer stem-like cell in vitro and in vivo. Integr Cancer Ther 17(4):1204-1215. https://doi.org/10.1177/1534735418786027

35. Roth MT, Cardin DB, Borazanci EH, Steinbach M, Picozzi VJ, Rosemury A, Wadlow RC, Newman RA, Berlin J (2020) A phase ii, single-arm, open-label, Bayesian adaptive efficacy and safety study of PBI-05204 in patients with stage IV metastatic pancreatic adenocarcinoma. Oncologist. https://doi. org/10.1634/theoncologist.2020-0440

36. Yu J, Chen Q (2014) Antitumor activities of Rauwolfia vomitoria extract and potentiation of gemcitabine effects against pancreatic cancer. Integr Cancer Ther 13(3):217-225. https://doi.org/10.1177/1534735414532010

37. Dong $R$, Chen $P$, Chen $Q$ (2018) Inhibition of pancreatic cancer stem cells by Rauwolfia vomitoria extract. Oncol Rep 40(6):3144-3154. https://doi.org/1 0.3892/or.2018.6713

38. Al Alawi R, Alhamdani MSS, Hoheisel JD, Baqi Y (2020) Antifibrotic and tumor microenvironment modulating effect of date palm fruit (Phoenix dactylifera L.) extracts in pancreatic cancer. Biomed Pharmacother 121: 109522. https://doi.org/10.1016/j.biopha.2019.109522

39. Mounid L, Gómez de Cedrón M, Vargas T, García-Carrascosa E, Herranz N, García-Risco M, Reglero G, Fornari T, Ramírez de Molina A (2018) Identification of antitumoral agents against human pancreatic cancer cells from Asteraceae and Lamiaceae plant extracts. BMC Complement Altern Med 18(1):254. https://doi.org/10.1186/s12906-018-2322-6

40. Mouhid L, Gómez de Cedrón M, García-Carrascosa E, Reglero G, Fornari T, Ramírez de Molina A (2019) Yarrow supercritical extract exerts antitumoral properties by targeting lipid metabolism in pancreatic cancer. PloS one 14(3):e0214294. https://doi.org/10.1371/journal.pone.0214294

41. Gómez de Cedrón M, Mouhid L, García-Carrascosa E, Fornari T, Reglero G, Ramírez de Molina A (2019) Marigold supercritical extract as potential coadjuvant in pancreatic cancer: the energetic catastrophe induced via BMP8B ends up with autophagy-induced cell death. Front Bioeng Biotechnol 7:455. https://doi.org/10.3389/fbioe.2019.00455

42. Zhang B, Zeng J, Yan Y, Yang B, Huang M, Wang L, Zhang Q, Lin N (2018) Ethyl acetate extract from Inula helenium $L$. inhibits the proliferation of pancreatic cancer cells by regulating the STAT3/AKT pathway. Mol Med Rep 17(4):5440-5448. https://doi.org/10.3892/mmr.2018.8534

43. Capistrano IR, Vangestel C, Vanpachtenbeke H, Fransen E, Staelens S, Apers S, Pieters $L$ (2016) Coadministration of a Gloriosa superba extract improves the in vivo antitumoural activity of gemcitabine in a murine pancreatic tumour model. Phytomedicine 23(12):1434-1440. https://doi.org/10.1016/j. phymed.2016.07.012

44. Dhar D, Raina K, Kant R, Wempe MF, Serkova NJ, Agarwal C, Agarwal R (2019) Bitter melon juice-intake modulates glucose metabolism and lactate efflux in tumors in its efficacy against pancreatic cancer. Carcinogenesis 40(9):1164-1176. https://doi.org/10.1093/carcin/bgz114

45. Liu J, Wang H, Wang J, Chang Q, Hu Z, Shen X, Feng J, Zhang Z, Wu X (2019) Total flavonoid aglycones extract in Radix Scutellariae induces crossregulation between autophagy and apoptosis in pancreatic cancer cells. J Ethnopharmacol 235:133-140. https://doi.org/10.1016/j.jep.2019.02.005

46. Sudha T, Mousa DS, El-Far AH, Mousa SA (2020) Pomegranate (Punica granatum) Fruit extract suppresses cancer progression and tumor angiogenesis of pancreatic and colon cancer in chick Chorioallantoic membrane model. Nutr Cancer:1-7. https://doi.org/10.1080/01635581.2020.1 800768

47. Cao H, Sethumadhavan K, Bland JM (2018) Isolation of cottonseed extracts that affect human cancer cell growth. Sci Rep 8(1):10458. https://doi.org/1 0.1038/s41598-018-28773-4

48. Tripathi SK, Biswal BK (2018) Pterospermum acerifolium (L.) wild bark extract induces anticarcinogenic effect in human cancer cells through mitochondrial-mediated ROS generation. Mol Biol Rep 45(6):2283-2294. https://doi.org/10.1007/s11033-018-4390-6

49. Hagoel L, Vexler A, Kalich-Philosoph L, Earon G, Ron I, Shtabsky A, Marmor S, Lev-Ari S (2019) Combined effect of Moringa oleifera and ionizing radiation on survival and metastatic activity of pancreatic cancer cells. Integr Cancer Ther 18:1534735419828829. https://doi.org/10.1177/1534735419828829

50. Li C, Xu H, Chen X, Chen J, Li X, Qiao G, Tian Y, Yuan R, Su S, Liu X, Lin X (2019) Aqueous extract of clove inhibits tumor growth by inducing autophagy through AMPK/ULK pathway. Phytother Res 33(7):1794-1804. https://doi.org/10.1002/ptr.6367
51. An EJ, Kim Y, Lee SH, Ko HM, Chung WS, Jang HJ (2020) Anti-cancer potential of Oxialis obtriangulata in pancreatic cancer cell through regulation of the ERK/Src/STAT3-mediated pathway. Molecules (Basel, Switzerland) 25(10). https://doi.org/10.3390/molecules25102301

52. Liu YH, Weng YP, Tsai HY, Chen CJ, Lee DY, Hsieh CL, Wu YC, Lin JY (2018) Aqueous extracts of Paeonia suffruticosa modulates mitochondrial proteostasis by reactive oxygen species-induced endoplasmic reticulum stress in pancreatic cancer cells. Phytomedicine 46:184-192. https://doi. org/10.1016/j.phymed.2018.03.037

53. Qian Y, Xiong Y, Feng D, Wu Y, Zhang X, Chen L, Gu M (2019) Coix seed extract enhances the anti-pancreatic cancer efficacy of gemcitabine through regulating $A B C B 1$ - and $A B C G 2$-mediated drug efflux: a bioluminescent pharmacokinetic and pharmacodynamic study. Int J Mol Sci 20(21). https://doi.org/10.3390/ijms20215250

54. Lee J, Lee J, Kim M, Kim JH (2018) Fermented extraction of citrus unshiu peel inhibits viability and migration of human pancreatic cancers. J Med Food 21(1):5-12. https://doi.org/10.1089/jmf.2017.3984

55. Sharan Shrestha S, Sut S, Ferrarese I, Barbon Di Marco S, Zengin G, De Franco M, Pant DR, Mahomoodally MF, Ferri N, Biancorosso N, Maggi F, Dall Acqua S, Rajbhandary S (2020) Himalayan Nettle Girardinia diversifolia as a candidate ingredient for pharmaceutical and nutraceutical applicationsphytochemical analysis and in vitro bioassays. Molecules (Basel, Switzerland) 25(7). https://doi.org/10.3390/molecules25071563

56. George S, Bhalerao SV, Lidstone EA, Ahmad IS, Abbasi A, Cunningham BT, Watkin KL (2010) Cytotoxicity screening of Bangladeshi medicinal plant extracts on pancreatic cancer cells. BMC Complement Altern Med 10:52. https://doi.org/10.1186/1472-6882-10-52

57. Subbarayan PR, Sarkar M, Impellizzeri S, Raymo F, Lokeshwar BL, Kumar P, Agarwal RP, Ardalan B (2010) Anti-proliferative and anti-cancer properties of Achyranthes aspera: specific inhibitory activity against pancreatic cancer cells. J Ethnopharmacol 131(1):78-82. https://doi.org/10.1016/j.jep.2010.06.002

58. Subbarayan PR, Sarkar M, Nagaraja Rao S, Philip S, Kumar P, Altman N, Reis Ahmed M, Ardalan B, Lokeshwar BL (2012) Achyranthes aspera (Apamarg) leaf extract inhibits human pancreatic tumor growth in athymic mice by apoptosis. J Ethnopharmacol 142(2):523-530. https://doi.org/10.1016/j.jep.2 012.05.030

59. Ovadje P, Chochkeh M, Akbari-Asl P, Hamm C, Pandey S (2012) Selective induction of apoptosis and autophagy through treatment with dandelion root extract in human pancreatic cancer cells. Pancreas 41(7):1039-1047. https://doi.org/10.1097/MPA.0b013e31824b22a2

60. Berkovich L, Earon G, Ron I, Rimmon A, Vexler A, Lev-Ari S (2013) Moringa Oleifera aqueous leaf extract down-regulates nuclear factor-kappaB and increases cytotoxic effect of chemotherapy in pancreatic cancer cells. BMC Complement Altern Med 13:212. https://doi.org/10.1186/1472-6882-13-212

61. Kaur M, Deep G, Jain AK, Raina K, Agarwal C, Wempe MF, Agarwal R (2013) Bitter melon juice activates cellular energy sensor AMP-activated protein kinase causing apoptotic death of human pancreatic carcinoma cells. Carcinogenesis 34(7):1585-1592. https://doi.org/10.1093/carcin/bgt081

62. Munro B, Vuong QV, Chalmers AC, Goldsmith CD, Bowyer MC, Scarlett CJ (2015) Phytochemical, antioxidant and anti-cancer properties of euphorbia tirucalli methanolic and aqueous extracts. Antioxidants (Basel, Switzerland) 4(4):647-661. https://doi.org/10.3390/antiox4040647

63. Akimoto M, lizuka M, Kanematsu R, Yoshida M, Takenaga K (2015) Anticancer effect of ginger extract against pancreatic cancer cells mainly through reactive oxygen species-mediated autotic cell death. Plos one 10(5):e0126605. https://doi.org/10.1371/journal.pone.0126605

64. Pan Y, Rhea P, Tan L, Cartwright C, Lee HJ, Ravoori MK, Addington C, Gagea M, Kundra V, Kim SJ, Newman RA, Yang P (2015) PBI-05204, a supercritical $\mathrm{CO} 2$ extract of Nerium oleander, inhibits growth of human pancreatic cancer via targeting the PI3K/mTOR pathway. Invest New Drugs 33(2):271279. https://doi.org/10.1007/s10637-014-0190-6

65. Goldsmith CD, Vuong QV, Sadeqzadeh E, Stathopoulos CE, Roach PD, Scarlett CJ (2015) Phytochemical properties and anti-proliferative activity of Olea europaea L. leaf extracts against pancreatic cancer cells. Molecules (Basel, Switzerland) 20(7):12992-13004. https://doi.org/10.3390/molecules2 00712992

66. Nguyen VT, Sakoff JA, Scarlett CJ (2017) Physicochemical, antioxidant, and cytotoxic properties of Xao Tam Phan (Paramignya trimera) root extract and its fractions. Chem Biodivers 14(4). https://doi.org/10.1002/cbdv.201600396

67. Nguyen VT, Sakoff JA, Scarlett CJ (2017) Physicochemical properties, antioxidant and cytotoxic activities of crude extracts and fractions from 
Phyllanthus amarus. Medicines (Basel) 4(2). https://doi.org/10.3390/ medicines 4020042

68. Minari JB, Okelola CA, Ugochukwu NC (2018) Analysis of Kras gene from induced pancreatic cancer rats administered with Momordicacharantia and Ocimumbasilicum leaf extracts. J Tradit Complement Med 8(2):282-288. https://doi.org/10.1016/j.jtcme.2017.04.003

69. Pham HNT, Sakoff JA, Bond DR, Vuong QV, Bowyer MC, Scarlett CJ (2018) In vitro antibacterial and anticancer properties of Helicteres hirsuta Lour. leaf and stem extracts and their fractions. Mol Biol Rep 45(6):2125-2133. https:// doi.org/10.1007/s11033-018-4370-x

70. Baena Ruiz R, Salinas Hernández P (2016) Cancer chemoprevention by dietary phytochemicals: epidemiological evidence. Maturitas 94:13-19. https://doi.org/10.1016/j.maturitas.2016.08.004

71. Chikara S, Nagaprashantha LD, Singhal J, Horne D, Awasthi S, Singhal SS (2018) Oxidative stress and dietary phytochemicals: role in cancer chemoprevention and treatment. Cancer Lett 413:122-134. https://doi.org/1 0.1016/j.canlet.2017.11.002

72. Davidson KT, Zhu Z, Fang Y (2016) Phytochemicals in the fight against cancer. Pathol Oncol Res 22(4):655-660. https://doi.org/10.1007/s12253016-0045-x

73. Ranjan A, Ramachandran S, Gupta N, Kaushik I, Wright S, Srivastava S, Das H, Srivastava S, Prasad S, Srivastava SK (2019) Role of phytochemicals in cancer prevention. Int J Mol Sci 20(20). https://doi.org/10.3390/ijms20204981

74. Efferth T, Saeed MEM, Mirghani E, Alim A, Yassin Z, Saeed E, Khalid HE, Daak $S$ (2017) Integration of phytochemicals and phytotherapy into cancer precision medicine. Oncotarget 8(30):50284-50304. https://doi.org/10.18632/ oncotarget.17466

75. Awale S, Dibwe DF, Balachandran C, Fayez S, Feineis D, Lombe BK, Bringmann G (2018) Ancistrolikokine E(3), a 5,8'-coupled naphthylisoquinoline alkaloid, eliminates the tolerance of cancer cells to nutrition starvation by inhibition of the Akt/mTOR/autophagy signaling pathway. J Nat Prod 81(10):2282-2291. https://doi.org/10.1021/acs.jnatprod. $8 \mathrm{~b} 00733$

76. Ma Y, Yu W, Shrivastava A, Alemi F, Lankachandra K, Srivastava RK, Shankar S (2017) Sanguinarine inhibits pancreatic cancer stem cell characteristics by inducing oxidative stress and suppressing sonic hedgehog-Gli-Nanog pathway. Carcinogenesis 38(10):1047-1056. https://doi.org/10.1093/carcin/ bg $\times 070$

77. Ji BL, Xia LP, Zhou FX, Mao GZ, Xu LX (2016) Aconitine induces cell apoptosis in human pancreatic cancer via NF-KB signaling pathway. Eur Rev Med Pharmacol Sci 20(23):4955-4964

78. Qian C, Chen X, Qi Y, Zhong S, Gao X, Zheng W, Mao Z, Yao J (2017) Sporamin induces apoptosis and inhibits NF-kB activation in human pancreatic cancer cells. Tumour Biol 39(7). https://doi.org/10.1177/101042 8317706917

79. Bhagya N, Chandrashekar KR, Prabhu A, Rekha PD (2019) Tetrandrine isolated from Cyclea peltata induces cytotoxicity and apoptosis through ROS and caspase pathways in breast and pancreatic cancer cells. In Vitro Cell Dev Biol Anim 55(5):331-340. https:/doi.org/10.1007/s11626-019-00332-9

80. Lee HS, Safe S, Lee SO (2017) Inactivation of the orphan nuclear receptor NR4A1 contributes to apoptosis induction by fangchinoline in pancreatic cancer cells. Toxicol Appl Pharmacol 332:32-39. https://doi.org/10.1016/j.taa p.2017.07.017

81. Hao C, Zhang X, Zhang H, Shang H, Bao J, Wang H, Li Z (2018) Sugiol (127horbar;hydroxyabieta-8,11,13-trien-7-one) targets human pancreatic carcinoma cells (Mia-PaCa2) by inducing apoptosis, G2/M cell cycle arrest, ROS production and inhibition of cancer cell migration. J BUON 23(1):205-210

82. Citi V, Piragine E, Pagnotta E, Ugolini L, Di Cesare ML, Testai L, Ghelardini C, Lazzeri L, Calderone V, Martelli A (2019) Anticancer properties of erucin, an H(2) S-releasing isothiocyanate, on human pancreatic adenocarcinoma cells (AsPC-1). Phytother Res 33(3):845-855. https://doi.org/10.1002/ptr.6278

83. Subramani R, Gonzalez E, Arumugam A, Nandy S, Gonzalez V, Medel J, Camacho F, Ortega A, Bonkoungou S, Narayan M, Dwivedi A, Lakshmanaswamy R (2016) Nimbolide inhibits pancreatic cancer growth and metastasis through ROS-mediated apoptosis and inhibition of epithelial-to-mesenchymal transition. Sci Rep 6:19819. https://doi.org/10.103 8/srep19819

84. Li Y, Gong L, Qi R, Sun Q, Xia X, He H, Ren J, Zhu O, Zhuo D (2017) Paeoniflorin suppresses pancreatic cancer cell growth by upregulating HTRA3 expression. Drug Des Devel Ther 11:2481-2491. https://doi.org/1 $0.2147 / D D D T . S 134518$
85. Chiu TL, Su CC (2017) Tanshinone IIA increases protein expression levels of PERK, ATF6, IRE1 a, CHOP, caspase-3 and caspase-12 in pancreatic cancer BxPC-3 cell-derived xenograft tumors. Mol Med Rep 15(5):3259-3263. https://doi.org/10.3892/mmr.2017.6359

86. Zhang Y, Xue YB, Li H, Qiu D, Wang ZW, Tan SS (2017) Inhibition of cell survival by curcumin is associated with downregulation of cell division cycle 20 (Cdc20) in pancreatic cancer cells. Nutrients 9(2). https://doi.org/10.3390/ nu9020109

87. Cheng H, Lu C, Tang R, Pan Y, Bao S, Qiu Y, Xie M (2017) Ellagic acid inhibits the proliferation of human pancreatic carcinoma PANC-1 cells in vitro and in vivo. Oncotarget 8(7):12301-12310. https://doi.org/10.18632/oncota rget.14811

88. Wei R, Penso NEC, Hackman RM, Wang Y, Mackenzie GG (2019) Epigallocatechin-3-Gallate (EGCG) suppresses pancreatic cancer cell growth, invasion, and migration partly through the Inhibition of Akt pathway and epithelial-mesenchymal transition: enhanced efficacy when combined with gemcitabine. Nutrients 11(8). https://doi.org/10.3390/nu11081856

89. Long J, Liu Z, Hui L (2019) Anti-tumor effect and mechanistic study of elemene on pancreatic carcinoma. BMC Complement Altern Med 19(1):133. https://doi.org/10.1186/s12906-019-2544-2

90. Fang K, Wang L, Chen L, Liu T, Fang Z (2019) Antiproliferative effects of matricine in gemcitabine-resistant human pancreatic carcinoma cells are mediated via mitochondrial-mediated apoptosis, inhibition of cell migration, invasion suppression, and mammalian target of rapamycin (mTOR)-TOR/ PI3K/AKT signalling pathway. Med Sci Monit 25:2943-2949. https://doi.org/1 0.12659/MSM.914244

91. Tuan Anh HL, Tran PT, Thao DT, Trang DT, Dang NH, Van Cuong P, Kiem PV, Minh CV, Lee JH (2018) Degalactotigonin, a steroidal glycoside from solanum nigrum, induces apoptosis and cell cycle arrest via inhibiting the egfr signaling pathways in pancreatic cancer cells. Biomed Res Int 2018: 3120972. https://doi.org/10.1155/2018/3120972

92. Rabi T, Catapano CV (2016) Aphanin, a triterpenoid from Amoora rohituka inhibits K-Ras mutant activity and STAT3 in pancreatic carcinoma cells. Tumour Biol 37(9):12455-12464. https://doi.org/10.1007/s13277-016-5102-2

93. Pei Z, Fu W, Wang G (2017) A natural product toosendanin inhibits epithelial-mesenchymal transition and tumor growth in pancreatic cancer via deactivating Akt/mTOR signaling. Biochem Biophys Res Commun 493(1): 455-460. https://doi.org/10.1016/j.bbrc.2017.08.170

94. Subramani R, Gonzalez E, Nandy SB, Arumugam A, Camacho F, Medel J, Alabi D, Lakshmanaswamy R (2017) Gedunin inhibits pancreatic cancer by altering sonic hedgehog signaling pathway. Oncotarget 8(7):10891-10904. https://doi.org/10.18632/oncotarget.8055

95. Carballo GB, Honorato JR, de Lopes GPF, Spohr T (2018) A highlight on Sonic hedgehog pathway. Cell Commun Signal 16(1):11. https://doi.org/1 0.1186/s12964-018-0220-7

96. Katoh M (2019) Genomic testing, tumor microenvironment and targeted therapy of Hedgehog-related human cancers. Clin Sci (Lond) 133(8):953970. https://doi.org/10.1042/CS20180845

97. Skoda AM, Simovic D, Karin V, Kardum V, Vranic S, Serman L (2018) The role of the Hedgehog signaling pathway in cancer: a comprehensive review. Bosn J Basic Med Sci 18(1):8-20. https://doi.org/10.17305/bjbms.2018.2756

98. Xu X, Lu Y, Li Y, Prinz RA (2017) Sonic Hedgehog signaling in thyroid cancer. Front Endocrinol (Lausanne) 8:284. https://doi.org/10.3389/fendo.2017.00284

99. Rimkus TK, Carpenter RL, Qasem S, Chan M, Lo HW (2016) Targeting the Sonic Hedgehog signaling pathway: review of smoothened and GLI inhibitors. Cancers (Basel) 8(2). https://doi.org/10.3390/cancers8020022

100. Kelleher FC (2011) Hedgehog signaling and therapeutics in pancreatic cancer. Carcinogenesis 32(4):445-451. https://doi.org/10.1093/carcin/bgq280

101. Lauth $M$, Toftgård R (2011) Hedgehog signaling and pancreatic tumor development. Adv Cancer Res 110:1-17. https://doi.org/10.1016/B978-0-12-3 86469-7.00001-3

102. Rosow DE, Liss AS, Strobel O, Fritz S, Bausch D, Valsangkar NP, Alsina J, Kulemann B, Park JK, Yamaguchi J, LaFemina J, Thayer SP (2012) Sonic Hedgehog in pancreatic cancer: from bench to bedside, then back to the bench. Surgery 152(3 Suppl 1):S19-S32. https://doi.org/10.1016/j.surg.2012. 05.030

103. Rangarajan P, Subramaniam D, Paul S, Kwatra D, Palaniyandi K, Islam S, Harihar S, Ramalingam S, Gutheil W, Putty S, Pradhan R, Padhye S, Welch DR, Anant S, Dhar A (2015) Crocetinic acid inhibits hedgehog signaling to inhibit pancreatic cancer stem cells. Oncotarget 6(29):27661-27673. https:// doi.org/10.18632/oncotarget.4871 
104. Yoneyama T, Arai MA, Sadhu SK, Ahmed F, Ishibashi M (2015) Hedgehog inhibitors from Withania somnifera. Bioorg Med Chem Lett 25(17):35413544. https://doi.org/10.1016/j.bmcl.2015.06.081

105. Averett C, Bhardwaj A, Arora S, Srivastava SK, Khan MA, Ahmad A, Singh S, Carter JE, Khushman M, Singh AP (2016) Honokiol suppresses pancreatic tumor growth, metastasis and desmoplasia by interfering with tumorstromal cross-talk. Carcinogenesis 37(11):1052-1061. https://doi.org/10.1093/ carcin/bgw096

106. Stone RC, Pastar I, Ojeh N, Chen V, Liu S, Garzon Kl, Tomic-Canic M (2016) Epithelial-mesenchymal transition in tissue repair and fibrosis. Cell Tissue Res 365(3):495-506. https://doi.org/10.1007/s00441-016-2464-0

107. Škovierová H, Okajčeková T, Strnádel J, Vidomanová E, Halašová E (2018) Molecular regulation of epithelial-to-mesenchymal transition in tumorigenesis (Review). Int J Mol Med 41(3):1187-1200. https://doi.org/10.3892/ijmm.2017.3320

108. Mittal V (2018) Epithelial mesenchymal transition in tumor metastasis. Annu Rev Pathol 13:395-412. https://doi.org/10.1146/annurev-pathol-020117-043854

109. Chen T, You Y, Jiang H, Wang ZZ (2017) Epithelial-mesenchymal transition (EMT): a biological process in the development, stem cell differentiation, and tumorigenesis. J Cell Physiol 232(12):3261-3272. https://doi.org/10.1002/ jcp.25797

110. Zhang Y, Weinberg RA (2018) Epithelial-to-mesenchymal transition in cancer: complexity and opportunities. Front Med 12(4):361-373. https://doi. org/10.1007/s11684-018-0656-6

111. Giannelli G, Koudelkova P, Dituri F, Mikulits W (2016) Role of epithelial to mesenchymal transition in hepatocellular carcinoma. J Hepatol 65(4):798808. https://doi.org/10.1016/j.jhep.2016.05.007

112. Du B, Shim JS (2016) Targeting epithelial-mesenchymal transition (EMT) to overcome drug resistance in cancer. Molecules (Basel, Switzerland) 21(7). https://doi.org/10.3390/molecules21070965

113. Wang S, Huang S, Sun YL (2017) Epithelial-mesenchymal transition in pancreatic cancer: a review. Biomed Res Int 2017:2646148. https://doi.org/1 $0.1155 / 2017 / 2646148$

114. Zhou P, Li B, Liu F, Zhang M, Wang Q, Liu Y, Yao Y, Li D (2017) The epithelial to mesenchymal transition (EMT) and cancer stem cells: implication for treatment resistance in pancreatic cancer. Mol Cancer 16(1): 52. https://doi.org/10.1186/s12943-017-0624-9

115. Beuran M, Negoi I, Paun S, Ion AD, Bleotu C, Negoi Rl, Hostiuc S (2015) The epithelial to mesenchymal transition in pancreatic cancer: a systematic review. Pancreatology 15(3):217-225. https://doi.org/10.1016/j. pan.2015.02.011

116. Sarkar S, Mandal C, Sangwan R, Mandal C (2014) Coupling G2/M arrest to the Wnt/B-catenin pathway restrains pancreatic adenocarcinoma. Endocr Relat Cancer 21(1):113-125. https://doi.org/10.1530/ERC-13-0315

117. Prasad R, Katiyar SK (2013) Grape seed proanthocyanidins inhibit migration potential of pancreatic cancer cells by promoting mesenchymal-toepithelial transition and targeting NF-KB. Cancer Lett 334(1):118-126. https://doi.org/10.1016/j.canlet.2012.08.003

118. Guha Majumdar A, Subramanian M (2019) Hydroxychavicol from Piper betle induces apoptosis, cell cycle arrest, and inhibits epithelial-mesenchymal transition in pancreatic cancer cells. Biochem Pharmacol 166:274-291. https://doi.org/10.1016/j.bcp.2019.05.025

119. Hoca M, Becer E, Kabadayı H, Yücecan S, Vatansever HS (2020) The effect of resveratrol and quercetin on epithelial-mesenchymal transition in pancreatic cancer stem cell. Nutr Cancer 72(7):1231-1242. https://doi.org/10.1080/0163 5581.2019 .1670853

120. Schafer KA (1998) The cell cycle: a review. Vet Pathol 35(6):461-478. https:// doi.org/10.1177/030098589803500601

121. Coffman JA (2004) Cell cycle development. Dev Cell 6(3):321-327. https:// doi.org/10.1016/s1534-5807(04)00067-x

122. Pack LR, Daigh LH, Meyer T (2019) Putting the brakes on the cell cycle: mechanisms of cellular growth arrest. Curr Opin Cell Biol 60:106-113. https://doi.org/10.1016/j.ceb.2019.05.005

123. Maitra A, Hruban RH (2008) Pancreatic cancer. Annu Rev Pathol 3:157-188. https://doi.org/10.1146/annurev.pathmechdis.3.121806.154305

124. Bayraktar S, Rocha Lima CM (2012) Emerging cell-cycle inhibitors for pancreatic cancer therapy. Expert Opin Emerg Drugs 17(4):571-582. https:// doi.org/10.1517/14728214.2012.739606

125. Liu Y, Bi T, Wang G, Dai W, Wu G, Qian L, Gao Q, Shen G (2015) Lupeol inhibits proliferation and induces apoptosis of human pancreatic cancer PCNA-1 cells through AKT/ERK pathways. Naunyn Schmiedebergs Arch Pharmacol 388(3):295-304. https://doi.org/10.1007/s00210-014-1071-4
126. Kim Y, Kim KH, Lee IS, Park JY, Na YC, Chung WS, Jang HJ (2019) Apoptosis and G2/M cell cycle arrest induced by a timosaponin A3 from Anemarrhena asphodeloides Bunge on AsPC-1 pancreatic cancer cells. Phytomedicine 56: 48-56. https://doi.org/10.1016/j.phymed.2018.08.006

127. Thoennissen NH, Iwanski GB, Doan NB, Okamoto R, Lin P, Abbassi S, Song JH, Yin D, Toh M, Xie WD, Said JW, Koeffler HP (2009) Cucurbitacin B induces apoptosis by inhibition of the JAK/STAT pathway and potentiates antiproliferative effects of gemcitabine on pancreatic cancer cells. Cancer Res 69(14):5876-5884. https://doi.org/10.1158/0008-5472.CAN-09-0536

128. Bhuyan DJ, Vuong QV, Bond DR, Chalmers AC, Bowyer MC, Scarlett CJ (2018) Eucalyptus microcorys leaf extract derived HPLC-fraction reduces the viability of MIA PaCa-2 cells by inducing apoptosis and arresting cell cycle. Biomed Pharmacother 105:449-460. https://doi.org/10.1016/j.biopha.2018. 05.150

129. Zhang M, Sun C, Shan X, Yang X, Li-Ling J, Deng Y (2010) Inhibition of pancreatic cancer cell growth by cucurbitacin B through modulation of signal transducer and activator of transcription 3 signaling. Pancreas 39(6): 923-929. https://doi.org/10.1097/MPA.0b013e3181ce719e

130. Lawrence $T$ (2009) The nuclear factor NF-kappaB pathway in inflammation. Cold Spring Harb Perspect Biol 1(6):a001651. https://doi.org/10.1101/ cshperspect.a001651

131. Mitchell S, Vargas J, Hoffmann A (2016) Signaling via the NFKB system. Wiley Interdiscip Rev Syst Biol Med 8(3):227-241. https://doi.org/10.1002/ wsbm.1331

132. Sun SC (2017) The non-canonical NF-KB pathway in immunity and inflammation. Nat Rev Immunol 17(9):545-558. https://doi.org/10.1038/nri.2 017.52

133. Tilborghs S, Corthouts J, Verhoeven Y, Arias D, Rolfo C, Trinh XB, van Dam PA (2017) The role of nuclear factor-kappa B signaling in human cervical cancer. Crit Rev Oncol Hematol 120:141-150. https://doi.org/10.1016/j. critrevonc.2017.11.001

134. Prabhu L, Mundade R, Korc M, Loehrer PJ, Lu T (2014) Critical role of NF-kB in pancreatic cancer. Oncotarget 5(22):10969-10975. https://doi.org/10.1 8632/oncotarget.2624

135. Pramanik KC, Makena MR, Bhowmick K, Pandey MK (2018) Advancement of NF-kB signaling pathway: a novel target in pancreatic cancer. Int J Mol Sci 19(12). https://doi.org/10.3390/ijms19123890

136. Kim SO, Kim MR (2013) [6]-Gingerol prevents disassembly of cell junctions and activities of MMPs in invasive human pancreas cancer cells through ERK/NF-K B/snail signal transduction pathway. Evid Based Complement Alternat Med 2013:761852. https://doi.org/10.1155/2013/761852

137. Hafeez BB, Jamal MS, Fischer JW, Mustafa A, Verma AK (2012) Plumbagin, a plant derived natural agent inhibits the growth of pancreatic cancer cells in in vitro and in vivo via targeting EGFR, Stat3 and NF-KB signaling pathways. Int J Cancer 131(9):2175-2186. https://doi.org/10.1002/ijc.27478

138. Johnson JL, de Mejia EG (2013) Flavonoid apigenin modified gene expression associated with inflammation and cancer and induced apoptosis in human pancreatic cancer cells through inhibition of GSK-3 $\beta / \mathrm{NF}-\mathrm{kB}$ signaling cascade. Mol Nutr Food Res 57(12):2112-2127. https://doi.org/10.1 002/mnfr.201300307

139. Cai X, Lu W, Yang Y, Yang J, Ye J, Gu Z, Hu C, Wang X, Cao P (2013) Digitoflavone inhibits $\mathrm{kBBa}$ kinase and enhances apoptosis induced by TNFa through downregulation of expression of nuclear factor KB-regulated gene products in human pancreatic cancer cells. PloS one 8(10):e77126. https:// doi.org/10.1371/journal.pone.0077126

140. Krajka-Kuźniak V, Cykowiak M, Szaefer H, Kleszcz R, Baer-Dubowska W (2020) Combination of xanthohumol and phenethyl isothiocyanate inhibits NF-kB and activates Nrf2 in pancreatic cancer cells. Toxicol In Vitro 65:104799. https://doi.org/10.1016/j.tiv.2020.104799

141. Nepstad I, Hatfield KJ, Grønningsæter IS, Reikvam H (2020) The PI3K-AktmTOR signaling pathway in human acute myeloid leukemia (AML) cells. Int J Mol Sci 21(8). https://doi.org/10.3390/ijms21082907

142. Xu F, Na L, Li Y, Chen L (2020) Roles of the PI3KJAKT/mTOR signalling pathways in neurodegenerative diseases and tumours. Cell Biosci 10:54. https://doi.org/10.1186/s13578-020-00416-0

143. Keppler-Noreuil KM, Parker VE, Darling TN, Martinez-Agosto JA (2016) Somatic overgrowth disorders of the PI3K/AKT/mTOR pathway \& therapeutic strategies. Am J Med Genet C Semin Med Genet 172(4):402421. https://doi.org/10.1002/ajmg.c.31531

144. Aoki M, Fujishita T (2017) Oncogenic roles of the PI3K/AKT/mTOR Axis. Curr Top Microbiol Immunol 407:153-189. https://doi.org/10.1007/82_2017_6 
145. Xia P, Xu XY (2015) PI3K/Akt/mTOR signaling pathway in cancer stem cells: from basic research to clinical application. Am J Cancer Res 5(5):1602-1609

146. O'Donnell JS, Massi D, Teng MWL, Mandala M (2018) PI3K-AKT-mTOR inhibition in cancer immunotherapy, redux. Semin Cancer Biol 48:91-103. https://doi.org/10.1016/j.semcancer.2017.04.015

147. Hubbard PA, Moody CL, Murali R (2014) Allosteric modulation of Ras and the PI3K/KT/mTOR pathway: emerging therapeutic opportunities. Front Physiol 5:478. https://doi.org/10.3389/fphys.2014.00478

148. Thillai K, Lam H, Sarker D, Wells CM (2017) Deciphering the link between PI3K and PAK: An opportunity to target key pathways in pancreatic cancer? Oncotarget 8(8):14173-14191. https://doi.org/10.18632/oncotarget.13309

149. Huang M, Tang SN, Upadhyay G, Marsh JL, Jackman CP, Shankar S, Srivastava RK (2014) Embelin suppresses growth of human pancreatic cancer xenografts, and pancreatic cancer cells isolated from KrasG12D mice by inhibiting Akt and Sonic hedgehog pathways. PloS one 9(4):e92161. https://doi.org/10.1371/journal.pone.0092161

150. Guo G, Yao G, Zhan G, Hu Y, Yue M, Cheng L, Liu Y, Ye Q, Qing G, Zhang Y, Liu H (2014) N-methylhemeanthidine chloride, a novel Amaryllidaceae alkaloid, inhibits pancreatic cancer cell proliferation via down-regulating AKT activation. Toxicol Appl Pharmacol 280(3):475-483. https://doi.org/10.1016/j. taap.2014.08.009

151. Seki T, Kokuryo T, Yokoyama Y, Suzuki H, Itatsu K, Nakagawa A, Mizutani T, Miyake T, Uno M, Yamauchi K, Nagino M (2011) Antitumor effects of abisabolol against pancreatic cancer. Cancer Sci 102(12):2199-2205. https:// doi.org/10.1111/j.1349-7006.2011.02082.x

152. Sun S, Phrutivorapongkul A, Dibwe DF, Balachandran C, Awale S (2018) Chemical constituents of Thai citrus hystrix and their antiausterity activity against the PANC-1 human pancreatic cancer cell line. J Nat Prod 81(8): 1877-1883. https://doi.org/10.1021/acs.jnatprod.8b00405

153. Zhou J, Zhao T, Ma L, Liang M, Guo YJ, Zhao LM (2017) Cucurbitacin B and SCH772984 exhibit synergistic anti-pancreatic cancer activities by suppressing EGFR, PI3K/Akt/mTOR, STAT3 and ERK signaling. Oncotarget 8(61):103167-103181. https://doi.org/10.18632/oncotarget.21704

154. Prasad R, Vaid M, Katiyar SK (2012) Grape proanthocyanidin inhibit pancreatic cancer cell growth in vitro and in vivo through induction of apoptosis and by targeting the PI3K/Akt pathway. PloS one 7(8):e43064. https://doi.org/10.1371/journal.pone.0043064

155. Zhang S, He F, Chen X, Ding K (2019) Isolation and structural characterization of a pectin from Lycium ruthenicum Murr and its antipancreatic ductal adenocarcinoma cell activity. Carbohydr Polym 223: 115104. https://doi.org/10.1016/j.carbpol.2019.115104

156. Lee J, Kim JH (2016) Kaempferol inhibits pancreatic cancer cell growth and migration through the blockade of EGFR-related pathway in vitro. PloS one 11(5):e0155264. https://doi.org/10.1371/journal.pone.0155264

157. Li X, Zhu F, Jiang J, Sun C, Wang X, Shen M, Tian R, Shi C, Xu M, Peng F, Guo X, Wang M, Qin R (2015) Synergistic antitumor activity of withaferin A combined with oxaliplatin triggers reactive oxygen species-mediated inactivation of the PI3K/AKT pathway in human pancreatic cancer cells. Cancer Lett 357(1):219-230. https://doi.org/10.1016/j.canlet.2014.11.026

158. Weston CR, Davis RJ (2007) The JNK signal transduction pathway. Curr Opin Cell Biol 19(2):142-149. https://doi.org/10.1016/j.ceb.2007.02.001

159. Zeke A, Misheva M, Reményi A, Bogoyevitch MA (2016) JNK signaling: regulation and functions based on complex protein-protein partnerships. Microbiol Mol Biol Rev 80(3):793-835. https://doi.org/10.1128/MMBR.00043-14

160. Gkouveris I, Nikitakis NG (2017) Role of JNK signaling in oral cancer: a mini review. Tumour Biol 39(6):1010428317711659. https://doi.org/10.1177/101 0428317711659

161. Kumar A, Singh UK, Kini SG, Garg V, Agrawal S, Tomar PK, Pathak P, Chaudhary A, Gupta P, Malik A (2015) JNK pathway signaling: a novel and smarter therapeutic targets for various biological diseases. Future Med Chem 7(15):2065-2086. https://doi.org/10.4155/fmc.15.132

162. Cui J, Zhang M, Zhang YQ, Xu ZH (2007) JNK pathway: diseases and therapeutic potential. Acta Pharmacol Sin 28(5):601-608. https://doi.org/1 0.1111/j.1745-7254.2007.00579.x

163. Chen $Q$, Li P, Li P, Xu Y, Li Y, Tang B (2015) Isoquercitrin inhibits the progression of pancreatic cancer in vivo and in vitro by regulating opioid receptors and the mitogen-activated protein kinase signalling pathway. Oncol Rep 33(2):840-848. https://doi.org/10.3892/or.2014.3626

164. Wang W, Cheng J, Zhu Y (2015) The JNK signaling pathway is a novel molecular target for S-propargyl- L-cysteine, a naturally-occurring garlic derivatives: link to its anticancer activity in pancreatic cancer in vitro and in vivo. Curr Cancer Drug Targets 15(7):613-623. https://doi.org/10.2174/1 568009615666150602143943

165. Li L, Zhao SL, Yue GGL, Wong TP, Pu JX, Sun HD, Fung KP, Leung PC, Han QB, Lau CBS, Leung PS (2018) Isodon eriocalyx and its bioactive component Eriocalyxin B enhance cytotoxic and apoptotic effects of gemcitabine in pancreatic cancer. Phytomedicine 44:56-64. https://doi.org/10.1016/j. phymed.2018.03.055

166. Fleisher TA (1997) Apoptosis. Ann Allergy Asthma Immunol 78(3):245-249: quiz 249-250. https://doi.org/10.1016/S1081-1206(10)63176-6

167. Elmore S (2007) Apoptosis: a review of programmed cell death. Toxicol Pathol 35(4):495-516. https://doi.org/10.1080/01926230701320337

168. Kaczanowski S (2016) Apoptosis: its origin, history, maintenance and the medical implications for cancer and aging. Phys Biol 13(3):031001. https:// doi.org/10.1088/1478-3975/13/3/031001

169. Pistritto G, Trisciuoglio D, Ceci C, Garufi A, D'Orazi G (2016) Apoptosis as anticancer mechanism: function and dysfunction of its modulators and targeted therapeutic strategies. Aging (Albany NY) 8(4):603-619. https://doi. org/10.18632/aging.100934

170. Erxleben A (2019) Mitochondria-targeting anticancer metal complexes. Curr Med Chem 26(4):694-728. https://doi.org/10.2174/09298673256661 80307112029

171. Neesse A, Gress TM, Michl P (2012) Therapeutic targeting of apoptotic pathways: novel aspects in pancreatic cancer. Curr Pharm Biotechnol 13(11): 2273-2282. https://doi.org/10.2174/138920112802501953

172. Fulda S (2009) Apoptosis pathways and their therapeutic exploitation in pancreatic cancer. J Cell Mol Med 13(7):1221-1227. https://doi.org/10.1111/ j.1582-4934.2009.00748.x

173. Liu Z, Li D, Zheng X, Wang E, Wang J (2013) Selective induction of apoptosis: promising therapy in pancreatic cancer. Curr Pharm Des 19(12): 2259-2268. https://doi.org/10.2174/1381612811319120013

174. Ma J, Fang B, Zeng F, Pang H, Ma C, Xia J (2015) Grape seed proanthocyanidins extract inhibits pancreatic cancer cell growth through down-regulation of miR-27a expression. Zhong Nan Da Xue Xue Bao Yi Xue Ban 40(1):46-52. https://doi.org/10.11817/j.issn.1672-7347.2015.01.008

175. Ma J, Fang B, Ma C, Pang H, Zeng F, Xia J (2015) Proanthocyanidins inhibit pancreatic cancer AsPC-1 cell growth and migration through up-regulation of let-7a. Nan Fang Yi Ke Da Xue Xue Bao 35(8):1110-1115

176. Jiang W, Zhao S, Xu L, Lu Y, Lu Z, Chen C, Ni J, Wan R, Yang L (2015) The inhibitory effects of xanthohumol, a prenylated chalcone derived from hops, on cell growth and tumorigenesis in human pancreatic cancer. Biomed Pharmacother 73:40-47. https://doi.org/10.1016/j.biopha.2015.05.020

177. Liu Z, Li D, Yu L, Niu F (2012) Gallic acid as a cancer-selective agent induces apoptosis in pancreatic cancer cells. Chemotherapy 58(3):185-194. https:// doi.org/10.1159/000337103

178. Angst E, Park JL, Moro A, Lu QY, Lu X, Li G, King J, Chen M, Reber HA, Go VL, Eibl G, Hines OJ (2013) The flavonoid quercetin inhibits pancreatic cancer growth in vitro and in vivo. Pancreas 42(2):223-229. https://doi.org/1 0.1097/MPA.0b013e318264ccae

179. Donald G, Hertzer K, Eibl G (2012) Baicalein--an intriguing therapeutic phytochemical in pancreatic cancer. Curr Drug Targets 13(14):1772-1776. https://doi.org/10.2174/138945012804545470

180. Cheung SSC, Hasman D, Khelifi D, Tai J, Smith RW, Warnock GL (2019) Devil's club falcarinol-type polyacetylenes inhibit pancreatic cancer cell proliferation. Nutr Cancer 71(2):301-311. https://doi.org/10.1080/01635581.2 018.1559931

181. Edderkaoui M, Lugea A, Hui H, Eibl G, Lu QY, Moro A, Lu X, Li G, Go VL, Pandol SJ (2013) Ellagic acid and embelin affect key cellular components of pancreatic adenocarcinoma, cancer, and stellate cells. Nutr Cancer 65(8): 1232-1244. https://doi.org/10.1080/01635581.2013.832779

182. Cedó L, Castell-Auví A, Pallarès V, Macià A, Blay M, Ardévol A, Motilva MJ, Pinent M (2014) Gallic acid is an active component for the anticarcinogenic action of grape seed procyanidins in pancreatic cancer cells. Nutr Cancer 66(1):88-96. https://doi.org/10.1080/01635581.2014.851714

183. Parasramka MA, Ali S, Banerjee S, Deryavoush T, Sarkar FH, Gupta S (2013) Garcinol sensitizes human pancreatic adenocarcinoma cells to gemcitabine in association with microRNA signatures. Mol Nutr Food Res 57(2):235-248. https://doi.org/10.1002/mnfr.201200297

184. Chung YC, Huang CC, Chen CH, Chiang HC, Chen KB, Chen YJ, Liu CL, Chuang LT, Liu M, Hsu CP (2012) Grape-seed procyanidins inhibit the in vitro growth and invasion of pancreatic carcinoma cells. Pancreas 41(3): 447-454. https://doi.org/10.1097/MPA.0b013e318229da41 
185. Dibwe DF, Awale S, Kadota S, Morita H, Tezuka Y (2013) Heptaoxygenated xanthones as anti-austerity agents from Securidaca longepedunculata. Bioorg Med Chem 21(24):7663-7668. https://doi.org/1 0.1016/j.bmc.2013.10.027

186. Tuan HN, Minh BH, Tran PT, Lee JH, Oanh HV, Ngo QMT, Nguyen YN, Lien PTK, Tran MH (2019) The effects of 2',4'-dihydroxy-6'-methoxy-3',5'dimethylchalcone from Cleistocalyx operculatus buds on human pancreatic cancer cell lines. Molecules (Basel, Switzerland) 24(14). https://doi.org/10.33 90/molecules 24142538

187. Luan YP, Li QF, Wu SG, Mao DC, Deng YY, Chen RW (2018) Tsoong induces apoptosis and inhibits proliferation, migration and invasion of pancreatic ductal adenocarcinoma cells. Mol Med Rep 17(3):3527-3536. https://doi. org/10.3892/mmr.2017.8328

188. Ravanan P, Srikumar IF, Talwar P (2017) Autophagy: the spotlight for cellular stress responses. Life Sci 188:53-67. https://doi.org/10.1016/j.lfs.2017.08.029

189. Shibutani ST, Saitoh T, Nowag H, Münz C, Yoshimori T (2015) Autophagy and autophagy-related proteins in the immune system. Nat Immunol 16(10):1014-1024. https://doi.org/10.1038/ni.3273

190. Saha S, Panigrahi DP, Patil S, Bhutia SK (2018) Autophagy in health and disease: a comprehensive review. Biomed Pharmacother 104:485-495. https://doi.org/10.1016/j.biopha.2018.05.007

191. Huang T, Song X, Yang Y, Wan X, Alvarez AA, Sastry N, Feng H, Hu B, Cheng SY (2018) Autophagy and hallmarks of cancer. Crit Rev Oncog 23(5-6):247267. https://doi.org/10.1615/CritRevOncog.2018027913

192. Levy JMM, Towers CG, Thorburn A (2017) Targeting autophagy in cancer. Nat Rev Cancer 17(9):528-542. https://doi.org/10.1038/nrc.2017.53

193. New M, Tooze S (2019) The role of autophagy in pancreatic cancer-recent advances. Biology (Basel) 9(1). https://doi.org/10.3390/biology9010007

194. Dibwe DF, Sun S, Ueda JY, Balachandran C, Matsumoto K, Awale S (2017) Discovery of potential antiausterity agents from the Japanese cypress Chamaecyparis obtusa. Bioorg Med Chem Lett 27(21):4898-4903. https:// doi.org/10.1016/j.bmcl.2017.09.034

195. Tawila AM, Sun S, Kim MJ, Omar AM, Dibwe DF, Ueda JY, Toyooka N, Awale $S$ (2020) Highly potent antiausterity agents from callistemon citrinus and their mechanism of action against the PANC-1 human pancreatic cancer cell line. J Nat Prod 83(7):2221-2232. https://doi.org/10.1021/acs.jnatprod. 0c00330

196. Yu L, Chen M, Zhang R, Jin Z (2019) Inhibition of cancer cell growth in gemcitabine-resistant pancreatic carcinoma by mangiferin phytochemical involves induction of autophagy, endogenous ROS production, cell cycle disruption, mitochondrial mediated apoptosis and suppression of cancer cell migration and invasion. J BUON 24(4):1581-1586

197. Li X, Zhu F, Jiang J, Sun C, Zhong Q, Shen M, Wang X, Tian R, Shi C, Xu M, Peng F, Guo X, Hu J, Ye D, Wang M, Qin R (2016) Simultaneous inhibition of the ubiquitin-proteasome system and autophagy enhances apoptosis induced by ER stress aggravators in human pancreatic cancer cells. Autophagy 12(9):1521-1537. https://doi.org/10.1080/15548627.2016.1191722

198. Ma J, Duan W, Han S, Lei J, Xu Q, Chen X, Jiang Z, Nan L, Li J, Chen K, Han L, Wang Z, Li X, Wu E, Huo X (2015) Ginkgolic acid suppresses the development of pancreatic cancer by inhibiting pathways driving lipogenesis. Oncotarget 6(25):20993-21003. https://doi.org/10.18632/oncotarget.3663

199. Gui Z, Li S, Liu X, Xu B, Xu J (2015) Oridonin alters the expression profiles of microRNAs in BxPC-3 human pancreatic cancer cells. BMC Complement Altern Med 15:117. https://doi.org/10.1186/s12906-015-0640-5

200. Fronza M, Lamy E, Günther S, Heinzmann B, Laufer S, Merfort I (2012) Abietane diterpenes induce cytotoxic effects in human pancreatic cancer cell line MIA PaCa-2 through different modes of action. Phytochemistry 78: 107-119. https://doi.org/10.1016/j.phytochem.2012.02.015

201. Yiallouris A, Patrikios I, Johnson EO, Sereti E, Dimas K, De Ford C, Fedosova NU, Graier WF, Sokratous K, Kyriakou K, Stephanou A (2018) Annonacin promotes selective cancer cell death via NKA-dependent and SERCAdependent pathways. Cell Death Dis 9(7):764. https://doi.org/10.1038/s4141 9-018-0772-x

202. Alilou M, Dibwe DF, Schwaiger S, Khodami M, Troppmair J, Awale S, Stuppner H (2020) Antiausterity activity of secondary metabolites from the roots of Ferula hezarlalehzarica against the PANC-1 human pancreatic cancer cell line. J Nat Prod 83(4):1099-1106. https://doi.org/10.1021/acs.jna tprod.9b01109

203. Pham H, Chen M, Takahashi H, King J, Reber HA, Hines OJ, Pandol S, Eibl G (2012) Apigenin inhibits NNK-induced focal adhesion kinase activation in pancreatic cancer cells. Pancreas 41(8):1306-1315. https://doi.org/10.1097/ MPA.0b013e31824d64d9

204. Cheng S, Castillo V, Sliva D (2019) CDC20 associated with cancer metastasis and novel mushroom-derived CDC20 inhibitors with antimetastatic activity. Int J Oncol 54(6):2250-2256. https://doi.org/10.3892/ijo.2019.4791

205. Omar AM, Dibwe DF, Tawila AM, Sun S, Phrutivorapongkul A, Awale S (2019) Chemical Constituents of Anneslea fragrans and their antiausterity activity against the PANC-1 human pancreatic cancer cell line. J Nat Prod 82(11):3133-3139. https://doi.org/10.1021/acs.jnatprod.9b00735

206. Kato A, Naiki-Ito A, Nakazawa T, Hayashi K, Naitoh I, Miyabe K, Shimizu S, Kondo H, Nishi Y, Yoshida M, Umemura S, Hori Y, Mori T, Tsutsumi M, Kuno T, Suzuki S, Kato H, Ohara H, Joh T, Takahashi S (2015) Chemopreventive effect of resveratrol and apocynin on pancreatic carcinogenesis via modulation of nuclear phosphorylated GSK3 $\beta$ and ERK1/2. Oncotarget 6(40): 42963-42975. https://doi.org/10.18632/oncotarget.5981

207. Zhou J, Liu M, Chen Y, Xu S, Guo Y, Zhao L (2019) Cucurbitacin B suppresses proliferation of pancreatic cancer cells by ceRNA: effect of miR146b-5p and IncRNA-AFAP1-AS1. J Cell Physiol 234(4):4655-4667. https://doi. org/10.1002/jcp. 27264

208. Iwanski GB, Lee DH, En-Gal S, Doan NB, Castor B, Vogt M, Toh M, Bokemeyer C, Said JW, Thoennissen NH, Koeffler HP (2010) Cucurbitacin B, a novel in vivo potentiator of gemcitabine with low toxicity in the treatment of pancreatic cancer. Br J Pharmacol 160(4):998-1007. https://doi.org/10.1111/ j.1476-5381.2010.00741.x

209. Patiño-Morales CC, Soto-Reyes E, Arechaga-Ocampo E, Ortiz-Sánchez E, Antonio-Véjar V, Pedraza-Chaverri J, García-Carrancá A (2020) Curcumin stabilizes p53 by interaction with NAD(P)H:quinone oxidoreductase 1 in tumor-derived cell lines. Redox Biol 28:101320. https://doi.org/10.1016/j. redox.2019.101320

210. Lee SY, Kim W, Lee YG, Kang HJ, Lee SH, Park SY, Min JK, Lee SR, Chung SJ (2017) Identification of sennoside A as a novel inhibitor of the slingshot (SSH) family proteins related to cancer metastasis. Pharmacol Res 119:422430. https://doi.org/10.1016/j.phrs.2017.03.003

211. Zheng M, Guo J, Xu J, Yang K, Tang R, Gu X, Li H, Chen L (2019) Ixocarpalactone A from dietary tomatillo inhibits pancreatic cancer growth by targeting PHGDH. Food Funct 10(6):3386-3395. https://doi.org/10.1039/ c9fo00394k

212. Zhao C, Wang D, Gao Z, Kan H, Qiu F, Chen L, Li H (2020) Licocoumarone induces BxPC-3 pancreatic adenocarcinoma cell death by inhibiting DYRK1A. Chem Biol Interact 316:108913. https://doi.org/1 0.1016/j.cbi.2019.108913

213. Lu QY, Zhang L, Yee JK, Go WW, Lee WN (2015) Metabolic Consequences of LDHA inhibition by Epigallocatechin Gallate and Oxamate in MIA PaCa-2 Pancreatic Cancer Cells. Metabolomics 11(1):71-80. https://doi.org/10.1007/ s11306-014-0672-8

214. Akasaka H, Mizushina Y, Yoshida K, Ejima Y, Mukumoto N, Wang T, Inubushi S, Nakayama M, Wakahara Y, Sasaki R (2016) MGDG extracted from spinach enhances the cytotoxicity of radiation in pancreatic cancer cells. Radiat Oncol 11(1):153. https://doi.org/10.1186/s13014-016-0729-0

215. Zheng X, Li D, Li J, Wang B, Zhang L, Yuan X, Li C, Cui L, Zhang Q, Yang L, Wang $X$ (2019) Optimization of the process for purifying icariin from Herba Epimedii by macroporous resin and the regulatory role of icariin in the tumor immune microenvironment. Biomed Pharmacother 118:109275. https://doi.org/10.1016/j.biopha.2019.109275

216. Aliebrahimi S, Kouhsari SM, Arab SS, Shadboorestan A, Ostad SN (2018) Phytochemicals, withaferin A and carnosol, overcome pancreatic cancer stem cells as c-Met inhibitors. Biomed Pharmacother 106:1527-1536. https:// doi.org/10.1016/j.biopha.2018.07.055

217. Gu M, Yu Y, Gunaherath GM, Gunatilaka AA, Li D, Sun D (2014) Structureactivity relationship (SAR) of withanolides to inhibit Hsp90 for its activity in pancreatic cancer cells. Invest New Drugs 32(1):68-74. https://doi.org/10.1 007/s10637-013-9987-y

218. Yu Y, Hamza A, Zhang T, Gu M, Zou P, Newman B, Li Y, Gunatilaka AA, Zhan CG, Sun D (2010) Withaferin A targets heat shock protein 90 in pancreatic cancer cells. Biochem Pharmacol 79(4):542-551. https://doi.org/10.1016/j. bcp.2009.09.017

219. Wei R, Hackman RM, Wang Y, Mackenzie GG (2019) Targeting glycolysis with epigallocatechin-3-gallate enhances the efficacy of chemotherapeutics in pancreatic cancer cells and xenografts. Cancers (Basel) 11(10). https://doi. org/10.3390/cancers 11101496 
220. Nwaeburu CC, Bauer N, Zhao Z, Abukiwan A, Gladkich J, Benner A, Herr I (2016) Up-regulation of microRNA let-7c by quercetin inhibits pancreatic cancer progression by activation of Numbl. Oncotarget 7(36):58367-58380. https://doi.org/10.18632/oncotarget.11122

221. Yang J, Wang F, Chen X, Qiu S, Cui L, Hu L (2019) $\beta$-Pentagalloyl-glucose sabotages pancreatic cancer cells and ameliorates cachexia in tumorbearing mice. Am J Chin Med 47(3):675-689. https://doi.org/10.1142/S01 $92415 \times 19500356$

222. Nguyen HX, Nguyen MTT, Nguyen TA, Nguyen NYT, Phan DAT, Thi PH, Nguyen THP, Dang PH, Nguyen NT, Ueda JY, Awale S (2013) Cleistanthane diterpenes from the seed of Caesalpinia sappan and their antiausterity activity against PANC-1 human pancreatic cancer cell line. Fitoterapia 91: 148-153. https://doi.org/10.1016/j.fitote.2013.08.018

223. Awale S, Linn TZ, Li F, Tezuka Y, Myint A, Tomida A, Yamori T, Esumi H, Kadota S (2011) Identification of chrysoplenetin from Vitex negundo as a potential cytotoxic agent against PANC-1 and a panel of 39 human cancer cell lines (JFCR-39). Phytother Res 25(12):1770-1775. https://doi.org/10.1002/ ptr.3441

224. Omar AM, Dibwe DF, Tawila AM, Sun S, Kim MJ, Awale S (2019) Chemical constituents from Artemisia vulgaris and their antiausterity activities against the PANC-1 human pancreatic cancer cell line. Nat Prod Res:1-7. https://doi. org/10.1080/14786419.2019.1700246

225. Nguyen HX, Do TN, Le TH, Nguyen MT, Nguyen NT, Esumi H, Awale S (2016) Chemical constituents of mangifera indica and their antiausterity activity against the PANC-1 human pancreatic cancer cell line. J Nat Prod 79(8):2053-2059. https://doi.org/10.1021/acs.jnatprod.6b00381

226. Barrajón-Catalán E, Fernández-Arroyo S, Saura D, Guillén E, FernándezGutiérrez A, Segura-Carretero A, Micol V (2010) Cistaceae aqueous extracts containing ellagitannins show antioxidant and antimicrobial capacity, and cytotoxic activity against human cancer cells. Food Chem Toxicol 48(8-9): 2273-2282. https://doi.org/10.1016/j.fct.2010.05.060

227. Nguyen NT, Nguyen MT, Nguyen HX, Dang PH, Dibwe DF, Esumi H, Awale S (2017) Constituents of the rhizomes of boesenbergia pandurata and their antiausterity activities against the PANC-1 human pancreatic cancer line. J Nat Prod 80(1):141-148. https://doi.org/10.1021/acs.jnatprod.6b00784

228. Qiao Y, Xu Q, Hu Z, Li XN, Xiang M, Liu J, Huang J, Zhu H, Wang J, Luo Z, Xue Y, Zhang Y (2016) Diterpenoids of the Cassane type from Caesalpinia decapetala. J Nat Prod 79(12):3134-3142. https://doi.org/10.1021/acs.jna tprod.6b00910

229. Awale S, Tawila AM, Dibwe DF, Ueda JY, Sun S, Athikomkulchai S, Balachandran C, Saiki I, Matsumoto K, Esumi H (2017) Highly oxygenated antiausterity agents from the leaves of Uvaria dac. Bioorg Med Chem Lett 27(9):1967-1971. https://doi.org/10.1016/j.bmcl.2017.03.021

230. Nguyen KDH, Dang PH, Nguyen HX, Nguyen MTT, Awale S, Nguyen NT (2017) Phytochemical and cytotoxic studies on the leaves of Calotropis gigantea. Bioorg Med Chem Lett 27(13):2902-2906. https://doi.org/10.1016/j. bmcl.2017.04.087

231. Atiya A, Sinha BN, Lal UR (2020) The new ether derivative of phenylpropanoid and bioactivity was investigated from the leaves of Piper betle L. Nat Prod Res 34(5):638-645. https://doi.org/10.1080/14786419.201 8.1495634

\section{Publisher's Note}

Springer Nature remains neutral with regard to jurisdictional claims in published maps and institutional affiliations.

\section{Submit your manuscript to a SpringerOpen ${ }^{\odot}$ journal and benefit from:}

- Convenient online submission

- Rigorous peer review

- Open access: articles freely available online

- High visibility within the field

- Retaining the copyright to your article

Submit your next manuscript at $\boldsymbol{\nabla}$ springeropen.com 